\title{
Oil price shocks and EMU sovereign yield spreads
}

\author{
Michail Filippidis ${ }^{1, *}$, George Filis ${ }^{2}$, Renatas Kizys $^{3}$ \\ ${ }^{1}$ Subject Group of Economics and Finance, Faculty of Business and Law, University \\ of Portsmouth, Portsmouth, PO1 3DE, UK. \\ ${ }^{2}$ Department of Accounting, Finance and Economics, Bournemouth University, \\ Bournemouth Business School, The Executive Business Centre, 89 Holdenhurst \\ Road, BH8 8EB, Bournemouth, UK. \\ ${ }^{3}$ Department of Banking and Finance, Southampton Business School, University of \\ Southampton, Highfield Campus, Southampton SO17 1BJ, United Kingdom \\ *Corresponding author: email: michail.filippidis@port.ac.uk.
}

\begin{abstract}
This study examines for the first time the relationship among the oil price shocks and the sovereign yield spreads in the EMU (which is collectively the largest oil-importer of the world), in a time-varying environment. In particular, we examine the timevarying correlation between oil price shocks and the 10-year sovereign yield spread of core and periphery countries in the EMU, by employing a scalar-BEKK framework. The main findings reveal that the correlations between sovereign yield spreads and oil price shocks are indeed time-varying and are influenced by specific economic and geopolitical events that took place during the study period. Furthermore, even though the correlation patterns are constantly low or zero prior to the Great Recession, a change is revealed in the post-2008 period, when correlations become moderate and more volatile. Finally, we do not observe noteworthy differences in the correlation behaviour between core and periphery countries to different oil price shocks. The findings of this study are particularly useful and provide valuable information to marketplace participants.
\end{abstract}

Keywords: EMU countries, EMU core and periphery, Oil price shocks, Scalar-BEKK, Time-varying correlation, 10-year sovereign yield spread

JEL classification: C22, C51, G13, G15, Q40 


\section{Introduction}

The oil market is of fundamental importance for the global economy. It is thus unsurprising that developments in the oil market are monitored and reported by the media $^{1}$ and they are at the core of debate among businesses, economists, governments, and financial market participants. ${ }^{2}$

Since the seminal paper by Hamilton (1983), there is a wealth of literature on the effects of oil price changes on economic activity. Indeed, developments in the oil market and consequently oil price fluctuations generate responses from macroeconomic indicators since oil is an important input in industrial production. Specifically, an increase in oil prices results in higher production costs or higher income (depending on the status of the economy as oil-importer or oil-exporter), which drives inflation towards higher levels. ${ }^{3}$ Additionally, higher oil prices may have a significant direct impact on government budgets. ${ }^{4}$ For instance, oil-exporting countries, due to higher income, are expected to experience improvements in their macroeconomic balances, whereas oilimporting countries are faced with uncertainty since increased oil prices could require government interventions, which could create budgetary risks.

In recent years, empirical works by Hamilton (2009a,b), Kilian (2009) and Kilian and Park (2009) have recognised the importance of exploring the origin of oil price shocks 5 and consequently the reactions of economic indicators and financial markets to these shocks. In this regard, a growing number of studies have analysed how the stock market

\footnotetext{
${ }^{1}$ See, for instance, (i) Iyengar (2018) in CNN who highlights the impact of recent increases in oil prices in the Indian economy, (ii) the report by Mackenzie, Blitz and Scaggs (2018) in Financial Times which asks whether oil rises point to a tipping point for bond yields, or (iii) the report by Liesman (2018) in CNBC which shows both the positive and negatives effects of rising oil prices in the US economy.

${ }^{2}$ See, for example, IMF's report by Arezki et al. (2017), IMF's (2016) World Economic Outlook, ECB's (2016) Economic Bulletin, the report by the UK's Office of Budget Responsibility (2015) or the report by the Joint Research Centre of the European Commission (2015).

${ }^{3}$ In this regard, we argue that inflation is generated regardless of the status of the economy as oilimporting or oil-exporting. For example, oil-importing countries experience cost-push inflation caused by rises in costs of production originated by higher oil prices. Similarly, oil-exporting countries also face increased inflation due to the higher income transferred from oil-importing countries. In this regard, the higher income allows the oil-exporting government to finance expansionary fiscal policies which stimulates aggregate demand and may lead to inflation.

${ }^{4}$ The impact of oil price changes on economic activity tends to be different when we consider the status of the country as oil-exporting or oil-importing. In this regard, economic activity of oil-exporting economies responds positively to higher oil prices. Specifically, an oil price increase is regarded as positive news through the higher government revenues (see, inter alia, Filis and Chatziantoniou, 2014; Wang et al., 2013; Arouri and Rault, 2012; Mohanty and Nandha, 2011).

${ }^{5}$ Since the seminal theoretical work by Barsky and Kilian $(2002,2004)$, the first structural analysis can be found to Kilian (2009), who argue that a supply-side shock is originated by changes in world oil production, an aggregate demand shock is attributed to changes in global demand for industrial commodities, and a precautionary demand shock is generated by concerns about the future availability of oil, arising from geopolitical unrest.
} 
performance responds to different oil price shocks. ${ }^{6}$ In short, the existing literature shows that positive aggregate demand shocks are associated with increases in economic activity and can be regarded as positive news for stock markets, driving their prices towards higher levels. In contrast, positive precautionary demand shocks are associated with increasing concerns about future oil supply shortfalls and a fall in economic activity, which is transmitted to stock markets, pushing them to bearish territories. Finally, stock markets do not seem to be significantly impacted by supply-side shocks. Despite this wealth of evidence on the relationship between oil prices (and shocks) and the wider economy or financial markets, the literature has remained relatively distant from the effects of the former on the sovereign risk of a country, as this is expressed by bond yield spreads. The interest in this relationship stems from the fact that oil prices and their shocks can be considered as sources of macroeconomic and financial instability, given their aforementioned effects (Bouri et al., 2018).

We further argue that it is not only the oil price shocks that might exert an impact on sovereign risk. Additionally, allowance should be made for the reverse channel, through which sovereign risk impacts oil prices, which appears to hold as well. In particular, the widening of sovereign risk spreads signifies a greater degree of default risk, which could subsequently lead to a reduction in aggregate demand and thus lower demand for oil. In addition, higher sovereign risk might lead to lower uncertainty about future oil supply shortfalls, given the lower demand for oil. Finally, higher sovereign risk could lead oil producers to limit oil supply and therefore a decrease in oil production is somewhat expected. However, unexpected changes in oil supply (disruptions) could be also considered as exogenous, driven by political events in oil-producing countries (see Kilian and Murphy, 2014). Overall, oil prices are expected to decline in response to an economic downturn.

The motivation for investigating the correlation between oil price shocks and sovereign yield spreads stems not only from the limited empirical research and the theoretical arguments, mentioned above, but also from reports by financial institutions ${ }^{7}$ and the

\footnotetext{
${ }^{6}$ Empirical evidence includes additional papers by Antonakakis et al. (2017), Kang et al. (2017), Angelidis et al. (2015), Kang et al. (2015), Antonakakis et al. (2014), Degiannakis et al. (2014), Filis (2014), Sadorsky (2014), Abhyankar et al. (2013), Antonakakis and Filis (2013), Baumeister and Peersman (2013), Chang et al. (2013), Gupta and Modise (2013), Wang et al. (2013), Basher et al. (2012), Broadstock et al. (2012), Filis et al. (2011), Kilian and Lewis (2011), Choi and Hammoudeh (2010), Apergis and Miller (2009), Kilian and Park (2009) and Hamilton (2009a,b).

${ }^{7}$ See, for instance the report by KfW (2017) titled "Oil prices and bond yields - hand-in-hand again".
} 
anecdotal evidence presented in the financial press $^{8}$, which place emphasis on the relationship between oil prices (or their shocks) and sovereign yield spreads. Similarly, it is no coincidence that the media suggests that lower oil prices present a serious challenge to US government debt as they are associated with a lower demand for US government bonds (CNBC, 2014), and that lower oil prices trigger a reduction in euro zone sovereign bond yields for both core and periphery countries, given their beneficial effects on inflation (Oxford Economics, 2014).

Nevertheless, the importance of the present study is also motivated by the EU's dependency on imported crude oil. Figure 1 depicts the oil import dependency for all $28 \mathrm{EU}$ member states, revealing that European countries import more than $80 \%$, on average, of their oil needs. Such a figure indicates the potential impact of oil price fluctuations on the import costs of these countries, exerting pressure on their trade balance and hence their economic performance.

\section{[PLEASE INSERT FIGURE 1 HERE]}

Against this background, the aim of this study is to contribute towards the limited investigation of the link between oil prices (or their shocks) and sovereign yield spreads. We attempt to satisfy this aim by assessing the relationship between sovereign risk and oil prices shocks using a time-varying framework. More specifically, this study employs the sovereign yield spreads as a numerical representation of sovereign risk. This choice is justified by the fact that sovereign yield spreads provide substantial information regarding a country's creditworthiness (the ability to serve its debt) and they are affected by unexpected changes to the key macroeconomic indicators and unexpected developments in the financial markets.

To date, there are only few studies that focus on this relationship, (see, for instance, Bouri et al., 2018, Bouri et al., 2017, Lee et al., 2017, Shahzad et al., 2017, Wegener et al., 2016, Aizenman et al., 2013, Alexandre and de Benoist, 2010). For example, Wegener et al. (2016) point out that higher oil prices contribute to reductions in the sovereign risk of oil-producing countries. Shahzad et al. (2017), on the other hand, show

\footnotetext{
${ }^{8}$ See for instance, the CNBC (2018) article titled "Treasury yields rise as surge in oil prices boost inflation outlook; jobs report misses expectations", the Reuters (2019) article title "Oil price rise pushes up euro zone debt yields" and Financial Times (2018) article titled "Do oil rises point to a tipping point for bond yields?”.
} 
that higher oil price volatility triggers an increase in the sovereign risk of oil-exporting countries. By distinguishing between oil-exporting and oil-importing countries, Lee et al. (2017) document that increasing oil prices cause a reduction (increase) in the sovereign risk of oil-exporters (importers). In a similar fashion, Bouri et al. (2018) show that the sovereign risk of oil-exporters (importers) is more sensitive to positive (negative) shocks in oil volatility. Nevertheless, the existing literature: i) provides limited evidence on the relationship between oil price movements and sovereign risk; ii) does not fully consider the heterogeneous effects of the different oil price shocks; and iii) is mainly based on a static rather than a dynamic environment.

Specifically, our contribution to the existing literature is threefold. First, this study sheds a new light on the relation between unanticipated changes in the oil price and sovereign yield spreads, measured as the difference in 10-year sovereign bond yields between members of the European Monetary Union and Germany. Second, this study examines the role of the origin of the oil price shocks in the aforementioned relation. To this end, we disentangle three structural oil price shocks: i) shocks to world oil supply; ii) oil price shocks arising from changes in aggregate demand; and iii) precautionary (or oil-market specific) demand shocks. Third, this study complements the existing literature by examining the relationship between oil price shocks and EMU sovereign yield spreads in a time-varying framework. ${ }^{9}$ To this end, we employ a set of core and periphery oil-importing members of the Economic and Monetary Union (EMU). It is worth noting that EMU is on aggregate the largest oil-importer in the world.

The distinction between core and periphery countries can be justified by the view that weaker periphery economies are expected to be more responsive to oil price fluctuations compared to stronger core economies (see Aizenman et al., 2013). Indeed, this could be the case for the periphery countries due to their: i) differences in terms of trade, compared to core countries (i.e. they run current account deficits); ii) slower adjustment to external shocks (see Celi et al., 2017); and iii) high dependence on imported energy (see Gibson et al., 2012).

\footnotetext{
${ }^{9} \mathrm{We}$ should notice that there is a recent evidence on the existing literature which indicates that the effect of oil prices on the economy and the stock market is likely time-varying (Boldanov et al., 2016; Broadstock and Filis, 2014; Filis, 2014; Antonakakis and Filis, 2013; Degiannakis et al., 2013; Filis et al., 2011; Bhar and Nikolova, 2010; Choi and Hammoudeh, 2010).
} 
The empirical methodology proceeds in two steps. In the first step, we estimate a structural VAR model, which helps us uncover the three structural oil price shocks, as in Kilian (2009). In the second step, we interplay the structural oil price shocks with sovereign yield spreads in a multivariate GARCH $(\mathrm{MGARCH})$ model. By way of the MGARCH model, we estimate the time-varying correlations among oil price shocks and sovereign yield spreads.

Our main findings reveal the following empirical regularities. First, correlations between sovereign yield spreads and different oil price shocks show a time-varying behaviour, which alternates between positive and negative values and exhibits heterogeneous patterns among the three shocks. Second, although correlations appear to fluctuate at relatively low values in the pre-2008 period, this pattern changes to relatively moderate and more volatile correlations in after 2008. Third, we do not produce noticeable evidence of differentiation in the correlation patterns of the sovereign yield spreads and different oil price shocks between core and periphery countries.

The rest of this paper is structured as follows. Section 2 discusses the existing literature in the field and presents the hypotheses under investigation. Section 3 describes the data used and provides a preliminary analysis. Section 4 presents the econometric model employed in this study. The empirical findings are reported and analysed in Section 5. Finally, Section 6 concludes the study.

\section{Brief review of the literature, theoretical channels between oil prices and} government bond yields and hypotheses development

\subsection{Brief review of the literature}

As was mentioned in Section 1, oil price changes exert a significant impact on the economy and trigger responses from macroeconomic indicators. Indeed, Hamilton (1983) was among the first to concentrate the attention of researchers on the important role that oil prices play in determining economic activity. Overall, there is a wealth of literature which provides empirical evidence that oil prices have significant effects on the economy. An in-depth review of the related literature can be found in Degiannakis et al. (2018).

In addition, since unexpected oil price changes appear to exert a significant impact on the economy, it is reasonable to ask whether oil price fluctuations affect the risk level of the economy. The existing literature along this line of research attempts to explore 
the channel which suggests that oil price movements are of consequence for sovereign risk. Some related studies which have considered this relationship include papers by Bouri et al. (2018), Bouri et al. (2017), Lee et al. (2017), Shahzad et al. (2017), Wegener et al. (2016), Aizenman et al. (2013) and Alexandre and de Benoist (2010).

In particular, Alexandre and de Benoist (2010) examine the effect of changes in oil prices on government bond risk premiums of emerging countries. They use the Emerging Market Bond Index Global (EMBIG) index as a measure of global risk. They employ a panel analysis and argue that the risk premium of government bonds is positively and significantly affected by higher oil prices. Concerning the EU market, Aizenman et al. (2013) employ a generalised method of moments approach and suggest that rises in world commodity prices and oil prices lead to lower sovereign CDS spreads. They argue that this could be explained by the fact that global economic conditions are largely strong when both prices are increasing. Furthermore, Wegener et al. (2016) use data from nine oil-producing countries to investigate the relationship between oil prices and sovereign CDS spreads. They employ bivariate VAR-GARCHin-mean models and document that positive oil price shocks lead to lower sovereign CDS spreads.

Additionally, Bouri et al. (2017) investigate the volatility transmission from commodities markets (including oil) to sovereign CDS spreads for a sample of emerging and frontier markets. They employ a Lagrange Multiplier methodology and report that sovereign CDS spreads are significantly affected by commodity price volatility. Moreover, Shahzad et al. (2017) examine the predictability from oil market uncertainty to the sovereign CDS spreads by using data from oil-exporting countries. They employ a modified bootstrap-rolling window approach and find a directional predictability from oil price volatility to sovereign CDS spreads. They conclude that higher oil price volatility contributes to increases in sovereign risk.

In a similar vein, Lee et al. (2017) investigate the relationship between oil price shocks and sovereign risk using the International Country Risk Guide (ICRG) data. They employ a Structural Vector Autoregressive model for a sample of oil-exporting and oilimporting countries. Specifically, they indicate that oil price shocks exert a reduction (increase) in sovereign risk for oil-exporting (oil-importing) countries. The authors highlight the importance of supply-side (demand-side) oil price shocks to the sovereign risk of net oil-exporting (oil-importing) countries. Finally, Bouri et al. (2018) examine the connection between oil price volatility shocks and sovereign risk for BRICS oil- 
exporting (Brazil and Russia) and oil-importing (China and India) countries. They employ a bivariate cross-quantilogram approach to measure the directional predictability and document that low (high) oil price volatility predicts low (high) sovereign risk.

In general, there is limited evidence on the relationship between oil price movements and sovereign risk. It should be noted that the aforementioned studies employ static econometric approaches. One notable exception is the study by Shahzad et al. (2017) who employ a time-varying approach based on the modified bootstrap rolling-window procedure. However, rolling-window approaches suffer from the identification of the appropriate window size and from weak expression of test statistics. Indeed, the shorter (longer) the rolling-window, the higher (lower) the irregular trends regarding the estimation of the model parameters and therefore the less (more) accurate parameter estimation would be. Furthermore, adding (deleting) one observation at the end (beginning) of the sample entails a loss of observations. In this regard, our time-varying framework does not suffer from these limitations.

\subsection{Theoretical channels between oil prices and government bond yields}

In attempting to better understand the importance of the relationship between oil prices and government bond yields, a number of theoretical channels by which oil price movements may interact with government bond yields changes are outlined here.

For instance, oil price changes can impact government bond yields via four potential channels, namely, (i) the production costs channel, (ii) inflation expectations channel, (iii) net exports channel and (iv) budget balance channel.

First, oil prices affect the production costs due to the fact that higher oil prices leads to increased production costs and thus lower production. This reduces the economic activity and hence deteriorates the growth prospects of an oil-importing economy, which is reflected in higher government bond yields. Second, oil prices affect inflation expectations because higher oil prices lead to higher consumer prices. Since oil is a major component of CPI, this leads to higher inflation expectations, which in turn puts an upward pressure on government bond yields. Third, higher oil prices increase import costs for oil-importers. This deteriorates net exports and thus the aggregate economic activity, which is reflected in higher government bond yields. Fourth, oil prices affect a budget balance, owing to the fact that higher oil prices trigger government spending 
through higher subsidies or energy spending. This leads to increased deficits or reduced surpluses, which in both cases results in higher government bond yields.

Overall, with reference to the theoretical transmission channels, through which oil price movements may affect the macroeconomic activity, and hence macroeconomic indicators, the reader is directed to authors such as Chen et al. (2014), Filis and Chatziantoniou (2014), Rahman and Serletis (2011), Segal (2011), Nakov and Pescatori (2010), Tang et al. (2010), Miller and Ratti (2009), Cologni and Manera (2008), Cunado and Perez de Gracia (2005).

In addition, government bond yields changes may also influence oil price movements, and hence the reverse channel seems to work. More specifically, government bond yields reflect the growth prospects of an economy. An economy that is growing, as reflected by decreasing government bond yields, has higher employment, which leads to higher income and thus spending. This stimulates production and, consequently, demand for production inputs. Oil is a major production input; therefore, its demand will increase, leading to a rise in oil prices.

Nevertheless, as previously mentioned, the literature in this area of research does not pay particular attention to the origin of the oil price shock in investigating the relationship between different oil price shocks and sovereign yield spreads. In our study, the latter represents the difference between the 10-year government bond yield, issued by an EMU member-country, and the German (Bund) 10-year bond yield. Having established the theoretical motivation between oil price changes and government bond yields, the aim of this study is to fill this void.

Overall, we examine the time-varying correlation between different oil price shocks based on their origin and the 10-year sovereign yield spread as a proxy of sovereign risk. We seek to expand the existing literature not only in terms of disaggregating the impact of oil price shocks on sovereign yield spreads but also in terms of investigating this relationship in a time-varying rather than a static econometric framework across EMU members.

\subsection{Hypotheses development}

Given the aforementioned literature, we focus on the anticipated time-varying correlation between sovereign yield spreads of core and periphery countries and oil price shocks. Thus, we posit the following hypotheses: 
Hypothesis 1: Negative correlations are anticipated between sovereign yield spreads and positive supply-side shocks.

Since both EMU core and periphery countries are oil-importing, we argue that an oil price decrease, due to increased oil production, promotes a drop in the cost of imported oil, which improves the current account balance. As a consequence of a reduction in the current account deficit there is reduced concern for the country to raise funds in order to service the external debt. In the case of such developments, spreads are expected to decrease since countries are expected to be more responsive relative to the benchmark country (e.g. Germany for the EMU member states), given that the yield of the latter has narrower variability margins.

Hypothesis 2: Negative correlations are anticipated between sovereign yield spreads and positive aggregate demand shocks.

A positive aggregate demand shock is associated with increases in economic activity and thus oil prices also increase. The higher economic activity, despite increased oil prices, contributes to a stable business and financial environment and reduces the uncertainty in the economy. Such developments are expected to have a greater positive impact on the least strong economies as opposed to the anchor country (e.g. Germany), leading to a decline in sovereign yield spreads.

Hypothesis 3: Positive correlations are anticipated between sovereign yield spreads and positive precautionary demand shocks.

More specifically, a positive precautionary demand shock represents fears about future oil supply shortfalls and therefore stimulates an increase in the oil price. This creates a weak business and financial environment, with a resultant fall in economic activity. This is expected to have negative impact to the least strong economies, with the consequence that the sovereign yield spread is expected to widen between the least strong economy and the benchmark country.

\section{Data description and preliminary analysis}

In this study, we use monthly data, from January 1999 to January 2016, on world oil production, a global economic activity index and the crude oil spot price for the purpose of estimating the three oil price shocks, as suggested by Kilian (2009), related to the supply of oil, aggregate demand and precautionary demand. The data for the world oil production are obtained from Energy Information Administration (EIA). Following Kilian (2009), we employ the global economic activity index with the aim of 
representing the global business cycle. Kilian provides a thorough explanation on his personal website of how this index is constructed. ${ }^{10}$ In addition, we choose the Brent crude oil price to serve as the spot price, considering that the Brent price is a global crude oil benchmark. Specifically, Brent is used to price crude oil that is produced and traded in different parts of the world such as Europe, the Mediterranean, Africa, as well as Australia and some Asian countries. ${ }^{11}$ Our decision to employ the Brent oil price is strongly motivated by the fact that this type of crude oil is extracted from the North Sea and mainly used locally in Europe. Data for the Brent crude oil price are collected from Datastream and are expressed in dollar terms. The oil (nominal) spot price is deflated by the US Consumer Price Index (CPI) in order to get the real oil price. The data on the CPI are available from the Bureau of Labor Statistics (BLS) of the United States.

In addition, we collect monthly data for the 10-year benchmark bond yields for eleven European countries, namely, Austria, Belgium, Finland, France, Germany, Greece, Ireland, Italy, Netherlands, Portugal and Spain. ${ }^{12,13}$ The data are retrieved from Datastream. We construct the 10-year sovereign yield spreads as the difference between the 10-year government bond yield issued by an EMU member-country and the German (Bund) 10-year bond yield (both yields of equal maturity). This choice is attributed to the fact that Germany's 10-year government bonds are considered to have the highest credit quality and liquidity (see Ejsing and Sihvonen, 2009).

The choice of the 10-year (long-term) sovereign yield spread is further justified by the fact that the longer the time to maturity, the larger the yield fluctuation (risk) and,

\footnotetext{
${ }^{10}$ The data for the global economic activity index are retrieved from Lutz Kilian's personal website: http://www-personal.umich.edu/ lkilian/

${ }^{11}$ The source of the information can be found on the EIA:

https://www.eia.gov/todayinenergy/detail.php?id=18571

${ }^{12}$ In this study, we consider the countries joined the EMU since 1999 and 2001 (the case of Greece). We do not include Luxembourg given that the government bond market of this country is relatively small (see Afonso et al., 2015) and the lack of data (see Maltritz, 2012). Furthermore, we exclude countries that joined EMU since 2007 (Slovenia (2007), Cyprus (2008), Malta (2008), Slovakia (2009), Estonia (2011), Latvia (2014) and Lithuania (2015)) due to short sovereign yield spreads data period. Finally, Germany is also excluded because is used as a reference country to construct the sovereign yield spreads for the rest countries.

${ }^{13}$ It should be mentioned that CDS spreads are commonly used in the existing literature to measure the sovereign risk. Nevertheless, our decision to use the 10-year sovereign yield spread as a proxy for sovereign risk is justified by the fact that it allows us to use a longer study period. In particular, the CDS data are available from 2009, whereas the data on the 10-year government bond yields for our selected countries are available since the creation of the EMU in 1999 (with the exception of Greece, which joined EMU in 2001). It should also be mentioned that, due to fiscal imbalances and fragilities among the EMU economies, and the need for the European Central Bank (ECB) to provide rescue packages to reduce the sovereign risk pressure, the 10-year sovereign yield spread may better approximate different fiscal fundamentals and could well capture uncertainty levels in the EMU economies.
} 
consequently, the greater the uncertainty in the market. Overall, the convergence of sovereign yield spreads is considered as a factor which reduces the uncertainty of allowing an immediate and less stressful access to debt financing by market participants in financial markets and motivates investment within converging countries (see Côté and Graham, 2004). This promotes the integration of the European bond markets and consequently endorses financial stability.

In addition, in order to address a potential omitted variable bias ${ }^{14}$, we collect data on the European economic policy uncertainty index, the European monetary policy uncertainty index, the European stock market volatility index and the realised oil price volatility, which impact both the bond yields and oil prices (see, for instance, Husted et al., 2017, Shahzad et al., 2017, Bernal et al., 2016, Afonso et al., 2015, Antonakakis et al., 2014, Anzuini et al., 2012, Barsky and Kilian, 2002, Arora and Cerisola, 2001). Monthly data for the European economic policy uncertainty index and the European stock market volatility index ${ }^{15}$ have been extracted from Datastream, whereas monthly data for the European monetary policy uncertainty index have been retrieved from the Federal Reserve database. ${ }^{16}$ Furthermore, the monthly oil price realised volatility is constructed using the daily data on the Brent crude oil price during the study period, which are obtained from Datastream. Section 4.2 describes the method employed for the construction of the monthly oil price realised volatility.

Thus, our sample consists of five EMU core countries (Austria, Belgium, Finland, France and Netherlands) and five EMU periphery countries (Greece, Ireland, Italy, Portugal and Spain). Considering the EMU core countries, our sample ranges from January 1999 to January 2016. The choice of the data period is motivated by the fact that all countries have belonged to the EMU since January 1999. It is worth noting that the data for Greece extend from January 2001, onwards, as the country joined the Eurozone in that year. Thus, a shorter period from January 2001 to January 2016 is under consideration for the EMU periphery countries. The period of analysis runs until January 2016 due to data availability for the European monetary policy uncertainty index that was devised by Husted et al. (2016b).

\footnotetext{
${ }^{14}$ We thank an anonymous reviewer for pointing out to this important issue.

${ }^{15}$ The European stock market volatility index (VSTOXX) represents the implied volatility of the EURO STOXX 50.

${ }^{16}$ Specifically, this index has been constructed by Husted et al. (2016b) for the ECB.
} 
Figures 2 and 3 exhibit the evolution of the series under consideration and show some interesting regularities. With reference to oil-related variables, the global economic activity index shows a tendency to increase during the period 2004-2007, which is influenced by the rising global demand for industrial commodities from emerging countries. Following this episode, we observe that it suffers a significant drop during the peak months of the Great Recession (i.e. late-2008), yet again reflecting the (negative) global economic conditions of this period. In addition, a significant trough is also observed during the period of 2014-2015, corresponding to the global economic slowdown. Furthermore, the graph of the real oil return features significant troughs and relatively high volatility within the years, 2001 (the terrorist attack of September 2001), 2003 (the second Iraq war), 2007-09 (the Great Recession) and 2014-2015. World oil production growth does not seem to show similar patterns and exhibits a relatively low and stable volatility (with the exception of the period 1999-2004, which is characterised by abrupt changes). The latter can be attributed to several decisions by OPEC to cut or raise production quotas, which were associated with the early-2000 recession, the terrorist attack of 9/11 (2001), the political unrest in Nigeria and Venezuela (both in 2003 ) and the second Iraq war (2003).

Turning to the evolution of sovereign yield spreads, we observe a convergence in performance, which is similar for all core and periphery countries, until the early stages of the Great Recession. Since 2008, though, we observe an increasing trend in all spreads, signifying the effects of the financial crisis since the collapse of the Lehman Brothers. This increasing pattern becomes more prevalent in the post-2010 period, which reflects the start of the European debt crisis, when Greece requested financial aid from the International Monetary Fund. In most cases, the spreads tend to exhibit a declining pattern in the post-2012 period. This could be explained by the effectiveness of fiscal stimulus policies that were undertaken by European governments in order to promote economic and financial stability in response to the debt crisis. In addition, the decreasing divergence can be further explained by the ECB announcement in 2015 to implement a quantitative easing (QE) programme, known as the Expanded Asset Purchase Programme (EAPP). ${ }^{17}$

\footnotetext{
${ }^{17}$ The aim of the EAPP by the ECB was to purchase sovereign bonds by issuing new reserves and providing liquidity in the distressed countries and therefore to generate a reduction in long-term interest rates in order to control the recession and promote stability.
} 
More specifically, the collapse of Lehman Brothers and especially the European debt crisis in post-2010 revealed the actual differences among the EMU countries that were not previously evident. In fact, differences in credit and liquidity risks influenced the government bond yields of the EMU countries and caused sovereign yield spreads to widen (see Dewachter et al., 2015). This confirms the argument that bonds that were issued by EMU countries should have never been considered as substitutes (see Favero, 2013). Overall, the period after the Great Recession indicated the vulnerability of the Eurozone and raised concerns about the macroeconomic and financial stability of core and periphery countries.

In this study, sovereign yield spreads reflect the differences between government bonds yields that were issued by EMU countries and the German Bund yield. The fact that sovereign yield spreads widened substantially during the peak months of the Great Recession emphasises the key role of Germany as the anchor country. Indeed, during this period of tightening financial conditions, the German Bund appeared to act as a 'flight-to-quality' government security for the market participants who traded in the European government bond markets. Specifically, German government bonds are characterised by safety and liquidity which explains why the German yield experienced a decreasing trend. ${ }^{18}$

It should be mentioned that government bond yields of core countries experienced a similar decreasing trend, but to a lesser extent, compared with the German Bund. This can be attributed to the fact that the government bonds of core countries were also regarded as relatively safe and liquid assets, although not comparable to the German Bund. However, the yields for the periphery countries exhibited increasing trends and appeared to be more unstable. A plausible explanation is that these bonds are perceived to be of lower quality compared with those bonds issued by core countries. Therefore,

\footnotetext{
${ }^{18}$ Ejsing and Sihvonen (2009) examine differences between German and French government bonds based on the fact that both bond markets are identical in terms of credit rating. They indicate that German bonds exhibited higher liquidity and a larger price premium which was more intense during the Great Recession. This can be explained by the fact that German bonds are deliverable into futures contracts in the very liquid German futures market, whereas French bonds are not delivered into futures contracts. Thus, significant liquidity spillovers from the German futures market to the German cash market could help to determine the differences between the two government bonds.
} 
differences in the quality possibly provide a plausible explanation for these unique asymmetric patterns of bond yields of core and periphery countries against the German Bund during the financial turmoil in the second half of 2008 and the European debt crisis in the post-2010 period. Figure 4 exhibits the differences in the evolution of sovereign bond yields in the EMU.

\section{[PLEASE INSERT FIGURE 4 HERE]}

Table 1 reports the descriptive statistics of the series. As expected, sovereign yield spreads of the periphery countries exhibit the highest volatility compared with those sovereign yield spreads of the core countries. This is indicated by their standard deviations. In addition, none of the series are normally distributed (with the exception of world oil production and the global economic activity index). This is clearly shown by values of the Jarque-Bera statistic, and standardised measures of skewness and kurtosis.

\section{[PLEASE INSERT TABLE 1 HERE]}

Table 2 summarises the results of the Augmented Dickey-Fuller (ADF) (Dickey and Fuller, 1981) and Phillips-Perron (PP) (Phillips and Perron, 1988) unit root tests. According to Panels A and B, there is present a unit root for all core and periphery countries' sovereign yield spreads. Applying a first-difference transformation, we achieve stationarity in these series. Similarly, world oil production and the oil spot price do not appear to be stationary in levels and thus the null hypothesis of unit root cannot be rejected. Thus, we proceed with the first difference transformation of these two variables. In contrast, the series on the global economic activity index is stationary by construction, since it reflects the global business cycle (Kilian and Murphy, 2014). Finally, the series on the control variables (European economic policy uncertainty index, the European monetary policy uncertainty index, the European stock market volatility index and the realised oil price volatility) are stationary, according to the results of the unit root tests.

[PLEASE INSERT TABLE 2 HERE] 
Table 3 reports the unconditional correlations among sovereign yield spreads (in first differences) and the three oil price shocks, based on a linear relationship. We notice that negative unconditional correlations are estimated between sovereign yield spreads and supply-side shocks (with the exception of Greece), as expected. In addition, contrary to our initial hypothesis, we observe positive unconditional correlations between sovereign yield spreads and aggregate demand shocks (with the exception of the Netherlands). It is also evident that the unconditional correlations between sovereign yield spreads and precautionary demand shocks are negative (with the exception of Ireland), which is also not anticipated. It should be noted that the findings from Table 3 hold for the whole period either for core or periphery countries. Furthermore, in Table 4 we report the unconditional correlations during the pre- and post-Great Recession periods, which clearly show a change in relationships, especially for the aggregate and precautionary demand shocks. These preliminary results motivate the use of a time-varying framework. Thus, in order to acquire a thorough picture about the time-varying correlations of the said relationships, a more in-depth analysis is carried out in Section $5 .{ }^{19}$

[PLEASE INSERT TABLES 3 AND 4 HERE]

\section{Methodology}

\subsection{Structural VAR model and historical decomposition}

To disaggregate different oil price shocks based on their origin, a SVAR model inspired by Kilian (2009) is employed. As previously mentioned, we decompose the oil price into supply-side shocks identified by changes in world oil production $\left(D P R O_{t}\right)$, aggregate demand shocks approximated by the global economic activity index $\left(G E A_{t}\right)$ and precautionary demand shocks represented by changes in the Brent real oil price $\left(D R O P_{t}\right)$. We highlight that $D$ represents the first difference between the values in month $t$ and month $t-i$.

The use of the SVAR requires imposing restrictions on the parameters which are indicating the contemporaneous relationships among the endogenous variables. These restrictions are used to identify the structural innovations of the model and are dictated

19 The Granger-causality test also confirms the relationship (either bidirectional or unidirectional) between oil price shocks and the 10-year government bond yield spreads. For brevity we do not show the results here, but they are available upon request. 
by the economic theory. Moreover, the impulse response analysis helps us ascertain the impact of an unexpected innovation in one endogenous variable on the other variables in the system. Expressed differently, we examine the response of an endogenous variable to a one standard deviation shock, to either itself or another variable entering the system.

The representation of the SVAR model of order $k$ (where the order $k$ denotes the maximum number of lag length reflected in the model) takes the following form:

$$
A_{0} Z_{t}=\alpha_{0}+\sum_{i=1}^{k} A_{i} Z_{t-i}+\varepsilon_{t}
$$

where $Z_{t}$ is the $(3 \times 1)$ vector of the three aforementioned endogenous variables, i.e. $Z_{t}=$ $\left(D P R O_{t}, G E A_{t}, D R O P_{t}\right), A_{0}$ represents the $(3 \times 3)$ matrix which includes the contemporaneous relations among the variables, $\alpha_{0}$ is the $(3 \times 1)$ vector of intercept (constant) terms, $A_{i}$ is the $(3 \times 3)$ matrix of coefficient parameters which need to be estimated for $i=1,2,3 \ldots . k, Z_{t-i}$ is the vector of lagged endogenous variables and $\varepsilon_{t}$ is a (3x1) vector of serially and mutually uncorrelated structural shocks (disturbances) which are assumed to have zero covariance.

In addition, the variance covariance matrix of the structural shocks can be illustrated as follows:

$$
\mathrm{E}\left(\varepsilon_{t} \varepsilon_{t}^{\prime}\right)=D=\left[\begin{array}{ccc}
\sigma_{S S}^{2} & 0 & 0 \\
0 & \sigma_{A D}^{2} & 0 \\
0 & 0 & \sigma_{P D}^{2}
\end{array}\right] .
$$

We emphasise that the variance covariance matrix of the structural shocks is diagonal, given that the structural shocks are assumed to be orthogonal and therefore mutually uncorrelated. In Equation 2, $E$ is the unconditional expectations operation, $\sigma^{2}$ is the variance of a random disturbance term and $D$ is a diagonal matrix.

To estimate the SVAR model, a reduced form representation is required to be implemented. Therefore, a reduced form representation of the SVAR model is indicated as:

$$
Z_{t}=\beta_{0}+\sum_{i=1}^{k} B_{i} Z_{t-i}+e_{t}
$$

This process implies that we multiply all parts of the equation (1) by $A_{0}^{-1}$. This process implies that $\beta_{0}=A_{0}^{-1} \alpha_{0}, B_{i}=A_{0}^{-1} A_{i}$, and $e_{t}=A_{0}^{-1} \varepsilon_{t}$. We notice that the reduced form errors (disturbance terms) $e_{t}$ are linear combinations of the structural shocks $\varepsilon_{t}$. 
In line with the previous analysis, the variance covariance matrix of the reduced form errors can be represented as:

$$
\begin{gathered}
E\left(e_{t} e_{t}^{\prime}\right)=E\left[\left(A_{0}^{-1} \varepsilon_{t}\right)\left(A_{0}^{-1} \varepsilon_{t}\right)^{\prime}\right]=E\left(A_{0}^{-1} \varepsilon_{t} \varepsilon_{t}^{\prime} A_{0}^{-1 \prime}\right)=A_{0}^{-1} E\left(\varepsilon_{t} \varepsilon_{t}^{\prime}\right) A_{0}^{-1 \prime}= \\
A_{0}^{-1} D A_{0}^{-1 \prime}=\Omega .
\end{gathered}
$$

It is worth noting that the reduced form errors are correlated across equations, which is in contrast with the structural shocks, and are assumed to be orthogonal and therefore mutually uncorrelated. A symmetric positive definite matrix $\Omega$ denotes that the entries above or below the principal diagonal are non-zero. In this regard, it is necessary to orthogonalise the reduced form errors by imposing a structural decomposition. Equation (5) shows how the vector of reduced form errors $\left(e_{t}\right)$ can be decomposed into structural disturbances $\left(\varepsilon_{t}\right)$ :

$$
e_{t}=\left[\begin{array}{c}
e_{D P R O, t} \\
e_{G E A, t} \\
e_{D R O P, t}
\end{array}\right]=A_{0}^{-1} \varepsilon_{t}=\left[\begin{array}{ccc}
\alpha_{11} & 0 & 0 \\
\alpha_{21} & \alpha_{22} & 0 \\
\alpha_{31} & \alpha_{32} & \alpha_{33}
\end{array}\right] \times\left[\begin{array}{c}
\varepsilon_{S S, t} \\
\varepsilon_{A D, t} \\
\varepsilon_{P D, t}
\end{array}\right],
$$

where, $\varepsilon_{S S, t}$ denotes the supply-side shocks originated from the world oil production, $\varepsilon_{A D, t}$ represents the aggregate demand shocks related to the global economic activity and $\varepsilon_{P D, t}$ indicates the precautionary demand shocks associated with the real oil price. Following Kilian (2009), we impose short-run restrictions on the lower triangular matrix $A_{0}^{-1}$ with the aim of detecting the structural shocks of the model. These shortrun restrictions allow us to set all entries located above the principal diagonal to zero. It must be mentioned that these short-run restrictions have been well demonstrated, explained and verified in Kilian's (2009) structural analysis.

The short-run restrictions which are imposed in Equation (5) are rationalised as follows. First, world oil production may not react contemporaneously to changes in global demand for industrial commodities and changes in oil prices. For this reason it takes time for the world oil production to adjust to these changes and consequently involves high adjustment costs. Nevertheless, world oil production responds contemporaneously to supply-side shocks. These short-run restrictions are observed in the first row as: $\alpha_{12}=0, \alpha_{13}=0$, and a non-zero $\alpha_{11}$. 
Second, global economic activity is not instantaneously influenced by changes in oil prices due to the sluggishness of global real economy to react to these changes. However, global economic activity is contemporaneously affected by supply-side shocks and aggregate demand shocks. Similarly, we observe these short-run restrictions in the second row as: $\alpha_{23}=0$, and a non-zero $\alpha_{21}$ and $\alpha_{22}$. Third, changes in oil prices are affected within the same month by supply-side shocks, aggregate demand shocks and its own innovations. We summarise that all types of shocks are allowed to contemporaneously impact oil prices. This is demonstrated by non-zero coefficients in the third row.

Next, we proceed to the historical decomposition in order to test the effects of the three oil price shocks on real oil price returns at each point in time. Given that the SVAR is already estimated, we follow Burbidge and Harrison (1985) who indicate that this technique involves three stages. Initially, a SVAR model is utilised to allow the identification of the three oil price shocks. Next, we forecast the endogenous variables. Finally, we decompose the forecast errors into the cumulative contributions of the structural oil price shocks. Thus, the cumulative effects from the three structural oil price shocks on the real oil returns are used as explanatory variables and allow identifying the importance of each shock at each point in time. To this end, Kilian and Park (2009) suggest that the computation of the historical decomposition is important in order to gain a clearer understanding of the cumulative effect of these shocks on the real oil returns.

\subsection{Scalar-BEKK model}

In order to investigate the dynamic correlation between different oil price shocks and the 10-year sovereign yield spread, a time-varying framework is adopted. The BabaEngle-Kraft-Kroner (BEKK) model described in Engle and Kroner (1995) and the dynamic conditional correlation (DCC) model introduced by Engle (2002) can be viewed as the most commonly used time-varying frameworks that successfully estimate dynamic conditional correlations between time series. Both models are considered as multivariate generalised autoregressive conditional heteroscedasticity (MGARCH) specifications. However, empirical evidence that has been supplied by Caporin and McAleer $(2008$, 2012) indicates the superiority of BEKK for estimating conditional correlations. Filis (2014) and Broadstock and Filis (2013) show respect for the empirical findings of Caporin and McAleer $(2008,2012)$ in their research regarding the 
use of time-varying models and underline the advantages of employing a BEKK model. Thus, we adopt a BEKK framework instead of using the DCC framework.

Turning our attention to the BEKK framework, we should not lose sight of the fact that a standard (general) BEKK contains a large number of parameters and computational problems. For example, a standard BEKK requires the estimation of $(n(n+1) / 2)+$ $2 n^{2}$ parameters. These issues are improved with the use of a scalar-BEKK in which the number of estimated parameters is significantly smaller as $(n(n+1) / 2)+2$ parameters require estimation.

The structure of the scalar-BEKK can be presented as:

$$
\begin{gathered}
\boldsymbol{y}_{t}=\boldsymbol{\mu}+\boldsymbol{\delta} \boldsymbol{X}_{t-1}+\boldsymbol{\varepsilon}_{t} \\
\boldsymbol{\varepsilon}_{t}=\boldsymbol{H}_{t}^{1 / 2} \boldsymbol{z}_{t} \\
\boldsymbol{z}_{t} \sim N I D\left(\mathbf{0}, \boldsymbol{I}_{N}\right) \\
\boldsymbol{H}_{t}=\boldsymbol{H}_{t}^{1 / 2}\left(\boldsymbol{H}_{t}^{1 / 2}\right)^{\prime}
\end{gathered}
$$

In this context, the $\left(\begin{array}{lll}n & 1\end{array}\right)$ vector $y_{t}$ relates to the multivariate stochastic process to be predicted and contains the variables of interest. Specifically, $\boldsymbol{y}_{t}=\left(y_{1, t}, y_{2, t}\right)^{\prime}$, where $y_{1, t}$ denotes each one of the oil price shocks and $y_{2, t}$ represents the 10 -year sovereign yield spread, at time $t$. Similarly, $\varepsilon_{t}=\left(\varepsilon_{1, t}, \varepsilon_{2, t}\right)^{\prime}$ is the vector of unexpected random shocks (errors) and reflects the innovations (news) for each variable at time $t$. Thus, the innovations are shocks to the variables of interest. Furthermore, the vector $\boldsymbol{\mu}$ represents the constant vector of means, $\boldsymbol{H}_{t}^{1 / 2}$ is a $(n \times n)$ matrix, which is obtained by a Cholesky decomposition, $\mathbf{z}_{t}$ is a $\left(\begin{array}{lll}n & \times & 1\end{array}\right)$ vector process which is assumed to follow a standard normal distribution such that $E\left(\mathbf{z}_{t}\right)=\mathbf{0}$ and $\operatorname{Var}\left(\mathbf{z}_{t}\right)=E\left(\mathbf{z}_{t} \mathbf{z}_{t}^{\prime}\right)=\boldsymbol{I}_{N}$ with the latter $\left(\boldsymbol{I}_{N}\right)$ to express an $(n \times n)$ identity matrix.

In the spirit of Degiannakis et al. (2016), a set of control variables $(\boldsymbol{X})$ are also included in the mean equation, in order to accommodate any omitted variable bias, as discussed in Section 3. In particular, vector $\boldsymbol{X}$ includes the European Economic Policy Uncertainty (EPU), European Monetary Policy Uncertainty (MPU), as well as stock market and oil price volatilities (VOL and ROV, respectively) ${ }^{20}$. Their inclusion allows us to separate

\footnotetext{
${ }^{20}$ Fiscal variables (such as cyclically adjusted net lending or government spending as $\%$ of GDP) could have been also considered in this line of research. Nevertheless, these variables are only available in quarterly or annual basis, which would significantly reduce the number of degrees of freedom in the
} 
any impact of the aforementioned variables on the time-varying relationship between oil price shocks and bond yield spreads. ${ }^{21}$ Finally, $\boldsymbol{\delta}$ denotes vector of coefficients to be estimated for each control variable. We also estimate the scalar-BEKK model excluding the vector of the control variables $(\boldsymbol{X})$ from the mean equation so to allow relevant comparisons.

The variance-covariance matrix, $\boldsymbol{H}_{t}$, is estimated assuming a first-order GARCH process, such as that:

$$
\boldsymbol{H}_{t}=\boldsymbol{C} \boldsymbol{C}^{\prime}+\boldsymbol{A} \varepsilon_{t-1} \boldsymbol{\varepsilon}_{t-1}^{\prime} \boldsymbol{A}^{\prime}+\boldsymbol{B} \boldsymbol{H}_{t-1} \boldsymbol{B}^{\prime}
$$

where $\boldsymbol{C}$ is an $(n \times n)$ lower triangular matrix, whereas the $\boldsymbol{A}$ and $\boldsymbol{B}$ are $(n \times n)$ square parameter matrices. Specifically, matrix $\boldsymbol{A}$ reflects the news shock and matrix $\boldsymbol{B}$ represents the persistence in conditional volatility.

In addition, as proposed by Ding and Engle (2001) the scalar-BEKK representation implies that $\boldsymbol{A}=\alpha \boldsymbol{I}_{N}$ and $\boldsymbol{B}=\beta \boldsymbol{I}_{N}$, where $\alpha$ and $\beta$ are positive scalars. Hence, $\boldsymbol{A}$ and $\boldsymbol{B}$ are matrices of ones and proportional to the $I_{N}$ and the scalar-BEKK can be written as:

$$
\boldsymbol{H}_{t}=\boldsymbol{C} \boldsymbol{C}^{\prime}+\alpha^{2}\left(\boldsymbol{\varepsilon}_{t-1} \boldsymbol{\varepsilon}_{t-1}^{\prime}\right)+\beta^{2} \boldsymbol{H}_{t-1}
$$

which in turn indicates a single parameter in each of the two matrices and consequently suggests the scalar-BEKK as the most restricted version of BEKK models. The matrix of constants is decomposed into two triangular matrices, $\boldsymbol{C}$ and $\boldsymbol{C}^{\prime}$, to ensure that $\boldsymbol{C} \boldsymbol{C}^{\prime}$ is a positive definite matrix. Consequently, $\boldsymbol{H}_{t}$ is also positive definite.

Finally, the time-varying correlation at time $t\left(\rho_{t}\right)$ between two series $i$ (10-year sovereign yield spread) and $j$ (each of the oil price shocks) is expressed as:

$$
\rho_{i j, t}=\frac{h_{i j, t}}{\sqrt{h_{i i, t}} \sqrt{h_{j j, t}}}
$$

model and would result in less accurate coefficient estimates. Moreover, adding further variables to our nonlinear model, defined in Equations $6-9$, would exacerbate the complexity of the log-likelihood function, resulting in the inability to achieve convergence to a global optimum.

${ }^{21}$ Despite the fact that the EPU, MPU and VOL are readily available, the ROV is constructed as follows: $R O V_{t}=100 \sqrt{12 \sum_{k=1}^{\tau}\left(\log R O P_{t_{k}}-\log R O P_{t_{k-1}}\right)^{2}}$, where $R O P_{t_{k}}$ denotes the real oil prices of day $k$ at month $t$. 
where the numerator expresses the non-diagonal element of $\boldsymbol{H}_{t}$ (the time-varying conditional covariance term between $i$ and $j$ ) and the denominator states the square roots of the diagonal elements of $\boldsymbol{H}_{t}$ (the time-varying conditional volatilities of $i$ and $j$ ). Overall, technical details for the estimation process of the scalar-BEKK are available in Xekalaki and Degiannakis (2010). Having explained the empirical framework, we further proceed to investigate the time-varying correlation between the variables under consideration.

\section{Empirical analysis}

\subsection{Historical decomposition of oil price shocks and the time-line of major events}

The historical decomposition of the real oil price returns and consequently the cumulative effect of supply-side shocks, aggregate demand shocks and precautionary demand shocks on the real oil price returns are presented in Figure 5. It is evident that precautionary demand shocks have a higher historical contribution, followed by aggregate demand shocks and then supply-side shocks. It is worth noting that the historical contribution of precautionary demand shocks has mainly fluctuated between $-20 \%$ and $20 \%$. Similarly, the percentage level of aggregate demand shocks has mostly ranged between $-5 \%$ and $5 \%$. Finally, the percentage contribution of supply-side shocks has not exceeded the level of $\pm 0.5 \%$. Overall, real oil returns appear to be more responsive to geopolitical events and generally fears about the future availability of oil. The higher magnitude of precautionary demand shocks at each point in time can be explained by the fact that geopolitical risk includes a broad range of interrelated events, such as political instability, military conflicts, terrorist attacks, civil wars, embargos, financial and macroeconomic uncertainty, supply constraints on commodities and other globally trade assets. On the other hand, aggregate demand shocks do not seem to influence significantly real oil returns until the onset of the Great Recession. These shocks appear to have a greater impact on the sharp fall in oil price during the period 2007-2009 and the period 2014-2015. Finally, supply-side shocks do not seem to contribute significantly to real oil returns since the magnitude is very small.

[PLEASE INSERT FIGURE 5 HERE] 
Next, we concentrate on specific events during which significant oil price movements (peaks and troughs) took place and generated either supply-side or demand-side oil price shocks. $^{22}$ Through a time-line, we pay particular attention to the early-2000 recession, the terrorist attack of 9/11 (2001), the second Iraq war (2003), the Atlantic hurricanes (late-2005), the increased demand for oil from emerging market countries such as China (2006-2007), the Great Recession (2007-2009), the European debt crisis (2010-2013), the Arab Spring together with continuing geopolitical turmoil in the Middle East (2011-2014) and finally the oil price crash (mid-2014 - early-2015). Linking these episodes with the oil price shocks, we note that supply-side shocks are typically associated with OPEC's decisions to cut or increase production quotas and natural disasters which cause a physical disruption in oil supply. On the other hand, aggregate demand shocks originate during turbulent economic periods, whereas precautionary demand shocks are linked with episodes of geopolitical uncertainty.

\subsection{Time-varying correlation between oil price shocks and sovereign yield spreads}

\subsubsection{Key research findings}

Figures 6 - 10 exhibit the time-varying correlations between each of the three oil price shocks and the 10-year sovereign yield spread of each core country, while Figures 11 15 display the time-varying correlations between each of the three oil price shocks and the 10-year sovereign yield spread of each periphery country. It should be mentioned that we observe the time-varying correlations having included the control variables to capture the omitted variable bias issue (solid line). Also, we provide the time-varying correlations having excluded the control variables (dashed line).

\section{[PLEASE INSERT FIGURES 6 - 15 HERE]}

Primarily, we focus our attention on some noteworthy features in order to paint an initial picture of the aforementioned relationship. It is evident that the correlations of both core and periphery countries are time-varying, which justifies the use of a dynamic

\footnotetext{
${ }^{22}$ Previous studies based on a time-line of major events in the oil market that investigate time-varying correlations between oil markets and stock markets include papers by Antonakakis et al. (2017), Boldanov et al. (2016), Broadstock and Filis (2014), Antonakakis and Filis (2013), Degiannakis et al. (2013) and Filis et al. (2011). A common feature of the aforementioned studies reveals that the correlations are time-varying, and the magnitude of the correlations differs at different events.
} 
rather than a static approach. Furthermore, we observe that the correlation patterns fluctuate and contain both positive and negative values. It is also apparent that correlations are influenced by the origin of the oil price shock and hence the trend of the correlations exhibits heterogeneous behaviour with respect to different oil price shocks during different time periods. More importantly, the differences in the two timevarying correlation lines suggest that the control variables are, on the whole, fundamental to determining the relationship between oil prices shocks and yield spreads. Therefore, these first observations provide support for the choice of our econometric framework and confirm that the origin of the oil price shock significantly matters to the correlation patterns and requires particular attention when we examine the link between oil prices and sovereign risk.

Turning our attention to country-specific time-varying correlations (focusing on the solid lines), it would seem that they do not provide support for our first hypothesis. In particular, the correlations are fluctuating very close to zero for all countries, except in the cases of France and Belgium (positive in the post-Great Recession period), as well as a clear negative correlation during 2001-2005, which is evident for all core countries. As far as the aggregate demand shocks are concerned, the results reveal that the second hypothesis seems to hold as on the whole, the correlations are negative. The only exception of substance is the 2009-2011 period, over which the correlations between aggregate demand shocks and yield spreads are positive. Finally, we maintain that our third hypothesis is largely confirmed since a positive correlation pattern is clearly exhibited for all countries, with very few exceptions (e.g., in France and Belgium during 2014-2015 and 2009, as well as in France, alone, during 2005-2006. Therefore, we document that the correlation patterns broadly show more conformity to our expectations regarding aggregate demand shocks and precautionary demand shocks, which reinforces our decision to construct and test three hypotheses.

It is interesting to observe that correlation levels are relatively close to zero until the beginning of the Great Recession, which primarily holds for the EMU periphery countries. This can be attributed to the fact that this period is closely related to the first years of transition to EMU and coincides with the convergence of sovereign bond yields (especially for the EMU periphery) and thus the minimisation of spreads (see, for example, Baele et al., 2004, Pagano and Von Thadden 2004, Codogno et al., 2003, Hartmann et al., 2003, Adam et al., 2002). Indeed, since the beginning of the transition until the early stage of the Great Recession, the difference between the 10-year bond 
yield issued by an EMU member-country and the German 10-year bond yield fluctuated within a very narrow range. In this regard, macroeconomic imbalances between core and periphery countries seemed to be ignored by the bond markets, which explains our findings of low or nearly zero correlation patterns between sovereign yield spreads and oil price shocks. Furthermore, our results interestingly suggest that since mid-2008 (which coincides with the most severe stage of the Great Recession) onwards, our correlations do not exhibit this low or almost zero patterns but instead they reveal moderate correlation levels with more volatile behaviour. Indeed, the deterioration of the macroeconomic fundamentals raised questions regarding the degree of financial integration of the European government bond markets and shed more light on the actual relationship between sovereign yield spreads and oil price shocks.

\subsubsection{Pre-Great Recession period}

We continue our analysis by investigating the time-varying correlations between the sovereign yield spreads of core and periphery countries and different oil price shocks during specific episodes that were identified in the previous section. Initially, we refer to the pre-Great Recession period.

The early-2000 period is characterised by a recession in the world's largest developed economies (US and EMU) and is primarily associated with a negative aggregate demand shock, pushing oil prices to lower levels. The negative correlations of the bond yield spreads with the latter shock are justified by the fact that German bond market was perceived as a safe heaven, relative to the other European bonds. This implies that bond yields exhibited an increasing trend. However, the German Bund was less responsive to this event in comparison with the bond yields of the rest of the countries. Since this period does not imply important supply-side or precautionary demand events, our findings mostly reveal evidence of no correlation between sovereign yield spreads and supply-side or precautionary demand shocks.

Next, we focus on the terrorist attack of September (9/11) 2001 in the US, which exerted a strong negative impact on not only economic activity in the US but also output in the global economy, and caused, primarily, a precautionary demand shock, driving the oil prices towards higher levels. Our findings indicate, on the whole, a positive correlation between sovereign yield spreads and precautionary demand shocks, which is, as has been mentioned, in line with our initial expectations. Such behaviour is expected given that European countries, which are among the most prominent trade partners with the 
US, are expected to be impacted by the geopolitical uncertainty caused by the terrorist attacks. Once again, though, it is anticipated that Germany's economy, and hence its bond, would be less sensitive than the remaining European government bonds, leading the bond yield spreads to higher levels.

The next period covers the second war in Iraq that occurred in 2003, which is indicative of geopolitical uncertainty related to concerns about oil supply disruptions and consequently has the interpretation of a precautionary demand shock. Our results illustrate the expected correlations between sovereign yield spreads and the three oil price shocks. Interestingly, though, the largest peaks in the correlations between yield spreads and precautionary demand shocks are observed for the core EMU countries. This might suggest that the specific event caused more turbulence to the economies of these countries rather than the EMU periphery.

Continuing our analysis, we concentrate on the late-2005 period which featured the impact of the three Atlantic hurricanes, Katrina (August), Rita (September) and Wilma (October), and triggered supply-side shocks. We observe that, even though the anticipated correlations between sovereign yield spreads and the two demand-side oil price shocks are evident, the correlations with the supply-side shocks are mainly very close to zero. A plausible explanation for such a finding can be traced to the empirical evidence which suggests that supply-side shocks do not seem to trigger any responses from the financial markets. This is in line with previous studies which have confirmed the insignificant effects of supply-side shocks on stock markets (see, inter alia, Degiannakis et al., 2014, Filis et al., 2011). Therefore, oil supply disruptions during this period does not appear to raise concerns in the European government bond markets.

Finally, the period 2006-2007 is largely associated with the Chinese economic growth (rising demand for oil) and more generally the growth of emerging economies, which caused positive aggregate demand shocks. Our findings mainly confirm the anticipated negative correlations between sovereign yield spreads and aggregate demand shocks, although it is apparent that the correlations of the periphery countries are closer to zero. In fact, during this period the bond yields of core EMU countries, vis-a-vis the German Bund, are decreasing, while a flat yield spread is evident for the periphery countries. Hence, we maintain that this behaviour explains the higher magnitude of the correlations of the core countries, relative to the almost zero correlation level of the periphery countries. Furthermore, such a finding may be also explained by the fact that the Chinese economy is engaging more with the core EMU countries. 


\subsubsection{During and after the Great Recession}

As far as the Great Recession (2007-2009) is concerned, we observe that during the second half of this period (i.e. late-2008 to 2009) a strong positive correlation (especially with the supply-side and aggregate demand shocks) between sovereign yield spreads and the three oil price shocks for all countries (with the exception of Belgium and France). This is a period when we experienced the collapse of the global oil prices from a peak of about $\$ 145$ to $\$ 30$ in less than a year, while at the same time bond yield spreads were also decreasing (particularly between German Bund and the bonds of the core EMU countries) in recognition that the Great Recession was coming to an end. The observed peak in most correlation figures during 2008-2009, while accommodating the effects of economic-related variables, provides further evidence of the close relationship between oil price shocks and bond yield spreads.

Continuing with the European debt crisis period that covers the remaining part of our sample period (2010-2016), we observe the considerable widening of the bond yield spreads, which coincided with several geopolitical events in the Middle East, as well as, the oil price slump in 2014-2015, when oil prices dropped by almost $75 \%$. Having removed the potential effects of the economic-related variables (such as EPU, MPU and VOL), our findings reveal that the EMU bond yield spreads are strongly positively related to the precautionary demand shocks caused by the Middle East unrest. At the same time, given that this period also triggered negative aggregate demand shocks in the oil market, we further observe the anticipated negative correlations between sovereign yield spreads and aggregate demand shocks, which is particularly evident for the EMU periphery, possibly due to the fact that these economies are more vulnerable to abrupt changes in the oil market.

In addition, our findings suggest that the correlations between sovereign yield spreads and supply-side shocks during 2010-2016 are virtually zero for all countries, with the exceptions of the positive correlations in the cases of Belgium and France. The Arab Spring caused precautionary demand oil price shocks, as was mentioned earlier, while at the same time the real oil disruptions of the period also triggered some supply-side shocks. The fact that only Belgium and the French bond yield spreads are associated with the supply-side shocks can be explained by the fact that these are the two countries within our sample that have the strongest links with the Arab oil producing countries. 
For instance, in 2015, about 34 million tons of crude oil which were imported to France came from the North Africa and the Middle East ${ }^{23}$.

Finally, with reference to the oil price slump of 2014-2015, it should be underlined that this period is dominated by aggregate demand shocks, as well as supply-side shocks. It is evident that during this period the correlation between bond yield spreads and precautionary demand shocks are reverting to zero, while the expected negative correlation with the aggregate demand shocks is mostly confirmed. Once again, the lack of strong correlations between the bond yield spreads and the supply-side shocks during 2014-2015 reveals the lack of importance of such shocks to the financial markets.

\subsubsection{Some further remarks}

Summarising our findings, we are able to point out one additional interesting feature. In particular, we do not observe noticeable differences in the correlation patterns between core and periphery countries, although more persistent positive or negative relationships are reported for the EMU periphery countries. A plausible explanation regarding the very little evidence of differentiation is that periphery countries appeared to be more dependent on oil imports (see, for instance, Gibson et al., 2012). In contrast, core countries might be less dependent on oil imports since they also use other sources of energy such as renewable or nuclear energy ${ }^{24}$. Reasonably, core countries will also be affected by oil price fluctuations. However, the magnitude of these responses is expected to be somewhat lower compared with those of periphery countries.

Hence, we provide support for a link between the oil market and sovereign risk. These new insights contribute greatly to the existing literature. For example, a number of recent studies which examine the link between oil and sovereign risk $^{25}$ (i) do not concentrate their attention on the substantial European market which is, on aggregate, the largest oil-importer in the world, (ii) have not considered the disaggregation of oil prices to the different oil price shocks and (iii) have underplayed the importance of the time-varying approach. However, we have convincingly shown in this study that the aforementioned relationship is dependent on not only the different oil price shocks but

\footnotetext{
${ }^{23}$ For more information, see: https://www.statista.com/statistics/745580/france-crude-oil-imported-byregion/

${ }^{24}$ The source of the information can be found on the Our Finite World site: https://ourfiniteworld.com/2012/03/05/why-high-oil-prices-are-now-affecting-europe-more-than-theus/\#comments

${ }^{25}$ See, Bouri et al. (2018), Bouri et al. (2017), Wegener et al. (2016) and Alexandre and de Benoist (2010), among others.
} 
also the different time periods when key economic and geopolitical events have taken place.

\section{Conclusion}

The aim of this study is to investigate the time-varying correlation between different shocks originating from the oil market and the 10-year sovereign yield spread of core and periphery countries in the EMU. We employ a set of five core countries (Austria, Belgium, Finland, France and Netherlands) and five periphery countries (Greece, Ireland, Italy, Portugal and Spain). In addition, we employ a set of control variables that impacts both the oil prices and sovereign yields, in order to capture the omitted variable bias issue. We use monthly data over the period from January 1999 to January 2016 for the core countries, whereas the sample period spans from January 2001 to January 2016 for the periphery countries. A scalar-BEKK time-varying framework is employed to explore the above relationship. Overall, this study expands the existing literature not only in examining the origin of the oil price change to test the aforementioned relationship but also in terms of introducing a time-varying rather than a static framework.

Our findings suggest some interesting empirical regularities. First, we cannot offer support to our first hypothesis regarding the negative correlation patterns between supply-side shocks and sovereign yield spreads. By contrast, our hypotheses regarding the two demand side shocks are generally supported by the evidence provided in this study. Second, the relationship between the different oil price shocks and sovereign yield spreads is indeed time-varying and depends on specific economic and geopolitical events that took place during the study period. Third, the correlation patterns appear to be less volatile in the pre-2008 period and passed into moderate and more volatile patterns in the post-2008 period. Finally, we do not observe important evidence of differentiation in the correlation patterns regarding the behaviour of core and periphery countries to different oil price shocks.

Our findings have important implications for financial market participants, in particular. For instance, it is worth noting that the time-varying correlations among oil price shocks and sovereign yield spreads could inform their dynamic asset allocation and portfolio diversification strategies. Therefore, although (high quality) sovereign bonds can act as a hedging instrument in periods of economic and geopolitical turmoil (see Bessler and Wolff, 2014), when bonds gain value, the degree to which they can be 
used to hedge risky investments will also depend on the oil price shocks over the period when such hedging is required. In addition, when contemplating investing in both oil and bond markets, consideration should be given to oil price developments, since aggregate demand shocks may serve in favour of great diversification opportunities (due to the negative correlations), whereas precautionary demand shocks could result in diminishing such opportunities (due to the positive correlations).

Further research may examine the time-varying relationship between oil prices (or their shocks) and the 10-year sovereign yield spread for economies that are not included in this study, such as Eastern European, North America, Asian and Latin America countries, as well as, for both oil-importing (i.e., China, Japan and the US) and oilexporting countries (i.e., Norway, Russia, Canada and Mexico). The use of CDS spreads as an alternative proxy to measure sovereign risk is another promising area for further research. Finally, another avenue for future research may be to consider the examination of the time-varying correlation between oil prices changes and short-term sovereign yield spreads.

\section{Acknowledgements}

We would like to thank the editor (Richard S.J. Tol) and two anonymous referees for their invaluable comments and suggestions on a previous version of this paper. We also thank Robert Gausden for his valuable comments on an earlier version of the paper. Finally, we would also like to thank the participants of the ISEFI 2019 conference. The usual disclaimer applies.

\section{References}

Abhyankar, A., Xu, B., \& Wang, J. (2013). Oil Price Shocks and the Stock Market: Evidence from Japan. Energy Journal, 34(2), 199-222.

Adam, K., Jappelli, T., Menichini, A., Padula, M., \& Pagano, M. (2002). Analyse, compare, and apply alternative indicators and monitoring methodologies to measure the evolution of capital market integration in the European Union. Report to the European Commission, 1-95.

Afonso, A., Arghyrou, M. G., Bagdatoglou, G., \& Kontonikas, A. (2015). On the timevarying relationship between EMU sovereign spreads and their determinants. Economic Modelling, 44, 363-371. 
Aizenman, J., Binici, M., \& Michael Hutchison, M. (2013) Credit ratings and the pricing of sovereign debt during the euro crisis. Oxford Review of Economic Policy, 29(3), 582-609.

Alexandre, H. and A. de Benoist (2010). Oil prices and government bond risk premiums. Lahore Journal of Business, 1(1), 1-21.

Angelidis, T., Degiannakis, S., \& Filis, G. (2015). US stock market regimes and oil price shocks. Global Finance Journal, 28, 132-146.

Antonakakis, N., Chatziantoniou, I., \& Filis, G. (2014). Dynamic spillovers of oil price shocks and economic policy uncertainty. Energy Economics, 44, 433-447.

Antonakakis, N., Chatziantoniou, I., \& Filis, G. (2017). Oil shocks and stock markets: Dynamic connectedness under the prism of recent geopolitical and economic unrest. International Review of Financial Analysis, 50, 1-26.

Antonakakis, N., \& Filis, G. (2013). Oil prices and stock market correlation: a timevarying approach. International Journal of Energy and Statistics, 1(01), 17-29.

Anzuini, A., Lombardi, M. J., \& Pagano, P. (2012). The impact of monetary policy shocks on commodity prices.

Apergis, N. \& Miller, S. M. (2009). Do structural oil-market shocks affect stock prices? Energy Economics, 31(4), 569- 575.

Arezki, M. R., Jakab, Z., Laxton, M. D., Matsumoto, M. A., Nurbekyan, A., Wang, H., \& Yao, J. (2017). Oil prices and the global economy. International Monetary Fund.

Arora, V., \& Cerisola, M. (2001). How does US monetary policy influence sovereign spreads in emerging markets?. IMF Staff papers, 48(3), 474-498.

Arouri, M. E. H., \& Rault, C. (2012). Oil prices and stock markets in GCC countries: empirical evidence from panel analysis. International Journal of Finance \& Economics, 17(3), 242-253.

Baele, L., Ferrando, A., Hördahl, P., Krylova, E., \& Monnet, C. (2004). Measuring financial integration in the euro area.

Barsky, R. B. and Kilian, L. (2002). Do We Really Know that Oil Caused the Great Stagflation? A Monetary Alternative. NBER Macroeconomics Annual 2001: 137-183.

Barsky, R. B. and Kilian, L. (2004). Oil and the Macroeconomy since the 1970s. Journal of Economic Perspectives, 18(4): 115-134. 
Basher, S.A, Haug, A. A. \& Sadorsky.P. (2012). Oil Prices, Exchange Rates and Emerging Stock Markets. Energy Economics, 34(1), 227-240.

Basher, S. A., Haug, A. A., \& Sadorsky, P. (2016). The impact of oil shocks on exchange rates: a Markov-switching approach. Energy Economics, 54, 11-23.

Baumeister, C., \& Peersman, G. (2013). Time-varying effects of oil supply shocks on the US economy. American Economic Journal: Macroeconomics, 5(4), 1-28.

Bernal, O., Gnabo, J. Y., \& Guilmin, G. (2016). Economic policy uncertainty and risk spillovers in the Eurozone. Journal of International Money and Finance, 65, 24-45.

Bessler, W., \& Wolff, D. (2014). Hedging European government bond portfolios during the recent sovereign debt crisis. Journal of International Financial Markets, Institutions and Money, 33, 379-399.

Bhar, R., \& Nikolova, B. (2010). Global oil prices, oil industry and equity returns: Russian experience. Scottish Journal of Political Economy, 57(2), 169-186.

Boldanov, R., Degiannakis, S., \& Filis, G. (2016). Time-varying correlation between oil and stock market volatilities: Evidence from oil-importing and oil-exporting countries. International Review of Financial Analysis, 48, 209-220.

Bouri, E., de Boyrie, M. E., \& Pavlova, I. (2017). Volatility transmission from commodity markets to sovereign CDS spreads in emerging and frontier countries. International Review of Financial Analysis, 49, 155-165.

Bouri, E., Shahzad, S. J. H., Raza, N., \& Roubaud, D. (2018). Oil volatility and sovereign risk of BRICS. Energy Economics, 70, 258-269.

Broadstock, D. C., Cao, H., \& Zhang, D. (2012). Oil shocks and their impact on energy related stocks in China. Energy Economics, 34(6), 1888-1895.

Broadstock, D. C., \& Filis, G. (2014). Oil price shocks and stock market returns: New evidence from the United States and China. Journal of International Financial Markets, Institutions and Money, 33, 417-433.

Burbidge, J., \& Harrison, A. (1985). An historical decomposition of the great depression to determine the role of money. Journal of Monetary Economics, $16(1), 45-54$.

Caporin, M., \& McAleer, M. (2008). Scalar BEKK and indirect DCC. Journal of Forecasting, 27(6), 537-549. 
Caporin, M., \& McAleer, M. (2012). Do we really need both BEKK and DCC? A tale of two multivariate GARCH models. Journal of Economic Surveys, 26(4), 736751.

Celi, G., Ginzburg, A., Guarascio, D., \& Simonazzi, A. (2017). Crisis in the European Monetary Union: A Core-periphery Perspective. Routledge.

Chang, C. L., McAleer, M., \& Tansuchat, R. (2013). Conditional correlations and volatility spillovers between crude oil and stock index returns. The North American Journal of Economics and Finance, 25, 116-138.

Chen, W., Hamori, S., \& Kinkyo, T. (2014). Macroeconomic impacts of oil prices and underlying financial shocks. Journal of International Financial Markets, Institutions and Money, 29, 1-12.

Choi, K., \& Hammoudeh, S. (2010). Volatility behavior of oil, industrial commodity and stock markets in a regime-switching environment. Energy Policy, 38(8), 4388-4399.

CNBC (2014). Oil price fallout: Producers struggle as GDP grows, by Jenny Cosgrave, December $11^{\text {th }}$, https://www.cnbc.com/2014/12/11/how-the-falling-oil-priceeffects-bond-yields-gdp-and-producers.html

CNBC (2018). Rising oil prices, once a big negative may now be a wash for the US economy, by S. Liesman May $14^{\text {th }}$, https://www.cnbc.com/2018/05/14/risingoil-prices-may-now-be-a-positive-for-the-us-economy.html

CNBC (2018). Treasury yields rise as surge in oil prices boost inflation outlook; jobs report misses expectations, by Thomas Franck December $7^{\text {th }}$, https://www.cnbc.com/2018/12/07/treasury-yields-move-ahead-of-nonfarmpayrolls.html

CNNMoney (2018). India is freaking out about rising oil prices, by Rishi Iyengar. May $18^{\text {th }}$, http://money.cnn.com/2018/05/18/news/economy/oil-prices-india-saudiarabia/index.html

Codogno, L., Favero, C., \& Missale, A. (2003). Yield spreads on EMU government bonds. Economic Policy, 18(37), 503-532.

Cologni, A., \& Manera, M. (2008). Oil prices, inflation and interest rates in a structural cointegrated VAR model for the G-7 countries. Energy economics, 30(3), 856888. 
Côté, D., \& Graham, C. (2004). Convergence of government bond yields in the Euro Zone: The role of policy harmonization. Bank of Canada. Working Paper 200423

Degiannakis, S., Duffy, D., Filis, G., \& Livada, A. (2016). Business cycle synchronisation in EMU: Can fiscal policy bring member-countries closer?. Economic Modelling, 52, 551-563.

Degiannakis, S., Filis, G., \& Arora, V. (2018). Oil Prices and Stock Markets: A Review of the Theory and Empirical Evidence. Energy Journal, 39(5).

Degiannakis, S., Filis, G., \& Floros, C. (2013). Oil and stock returns: Evidence from European industrial sector indices in a time-varying environment. Journal of International Financial Markets, Institutions and Money, 26, 175-191.

Degiannakis, S., Filis, G., \& Kizys, R. (2014). The Effects of Oil Price Shocks on Stock Market Volatility: Evidence from European Data. Energy Journal, 35(1), 3536.

Dewachter, H., Iania, L., Lyrio, M., \& de Sola Perea, M. (2015). A macro-financial analysis of the euro area sovereign bond market. Journal of Banking \& Finance, 50, 308-325.

Dickey, D.A., \& Fuller, W.A. (1981). Likelihood ratio statistics for autoregressive time series with a unit root. Econometrica, 49(4), 1057-1072.

Ding, Z., \& Engle, R. F. (2001). Large scale conditional covariance matrix modelling, estimation and testing. Academia Economic Papers, 29, 157-184.

ECB (2016). Global implications of low oil prices. Economic Bulletin, Issue 4.

Ejsing, J.W., Sihvonen, J., (2009). Liquidity Premia in German Government Bonds. European Central Bank Working Paper 1081.

Engle, R. (2002). Dynamic conditional correlation: A simple class of multivariate generalized autoregressive conditional heteroskedasticity models. Journal of Business \& Economic Statistics, 20(3), 339-350.

Engle, R. F., \& Kroner, K. F. (1995). Multivariate simultaneous generalized ARCH. Econometric theory, 11(1), 122-150.

Eurostat (2018). Oil and petroleum products - a statistical overview.

Favero, C. A. (2013). Modelling and forecasting government bond spreads in the euro area: a GVAR model. Journal of Econometrics, 177(2), 343-356.

Filis, G. (2014). Time-varying co-movements between stock market returns and oil price shocks. International Journal of Energy and Statistics, 2(01), 27-42. 
Filis, G., \& Chatziantoniou, I. (2014). Financial and monetary policy responses to oil price shocks: evidence from oil-importing and oil-exporting countries. Review of Quantitative Finance and Accounting, 42(4), 709-729.

Filis, G., Degiannakis, S., \& Floros, C. (2011). Dynamic correlation between stock market and oil prices: The case of oil-importing and oil-exporting countries. International Review of Financial Analysis, 20(3), 152-164.

Financial Times (2018). Do oil rises point to a tipping point for bond yields? By Michael Mackenzie, Roger Blitz and Alexandra Scaggs. April, 22 ${ }^{\text {nd }}$. https://www.ft.com/content/d1427264-4482-11e8-93cf-67ac3a6482fd.

Gibson, H.D., Stephen G. Hall, S.G., \& George S. Tavlas, G.S. (2012) The Greek financial crisis: Growing imbalances and sovereign spreads. Journal of International Money and Finance, 31(3), 498-516.

Gupta, R., \& Modise, M. P. (2013). Does the source of oil price shocks matter for South African stock returns? A structural VAR approach. Energy Economics, 40, 825831.

Hamilton, J. D. (1983). Oil and the macroeconomy since World War II. Journal of political economy, 91(2), 228-248.

Hamilton, J. D. (2009a). Causes and Consequences of the Oil Shock of 2007-08. Brookings Papers on Economic Activity, 40(1), 215-261.

Hamilton, J. D. (2009b). Understanding Crude Oil Prices. Energy Journal, 30(2), 179206.

Hartmann, P., Maddaloni, A., \& Manganelli, S. (2003). The Euro-area Financial System: Structure, Integration, and Policy Initiatives. Oxford Review of Economic Policy, 19(1), 180-213.

Husted, L. F., Rogers, J. H., \& Sun, B. (2016b). Measuring Cross Country Monetary Policy Uncertainty (No. 2016-11-23). Board of Governors of the Federal Reserve System (US).

International Monetary Fund (2016). World Economic Outlook: Too Slow for Too Long. Washington, April.

Jones, C. M., \& Kaul, G. (1996). Oil and the stock markets. The Journal of Finance, 51(2), 463-491.

Kang, W., de Gracia, F. P., \& Ratti, R. A. (2017). Oil price shocks, policy uncertainty, and stock returns of oil and gas corporations. Journal of International Money and Finance, 70, 344-359. 
Kang, W., Ratti, R. A., \& Yoon, K. H. (2015). The impact of oil price shocks on the stock market return and volatility relationship. Journal of International Financial Markets, Institutions and Money, 34, 41-54.

KfW (2017). Oil prices and bond yields, hand-in-hand again, by Sebastian Wanke, July2 $7^{\text {th }}$,https://www.kfw.de/PDF/DownloadCenter/Konzernthemen/Researc h/PDF-Dokumente-Volkswirtschaft-Kompakt/One-Pager-2017-EN/VK-No.140-July-2017-Oil-prices-and-bond-yields.pdf

Kilian, L. (2009). Not all oil price shocks are alike: Disentangling demand and supply shocks in the crude oil market. The American Economic Review, 99(3), 10531069.

Kilian, L., \& Lewis, L. T. (2011). Does the Fed respond to oil price shocks?. The Economic Journal, 121(555), 1047-1072.

Kilian, L., \& Murphy, D. P. (2014). The role of inventories and speculative trading in the global market for crude oil. Journal of Applied Econometrics.

Kilian, J \& Park, C. (2009). The Impact of Oil Price Shocks on the U.S. Stock Market, International Economic Review, 50(4), 1267-1287.

Lee, C. C., Lee, C. C., \& Ning, S. L. (2017). Dynamic relationship of oil price shocks and country risks. Energy Economics, 66, 571-581.

Maltritz, D. (2012). Determinants of sovereign yield spreads in the Eurozone: A Bayesian approach. Journal of International Money and Finance, 31(3), 657672.

Miller, J. I., \& Ratti, R. A. (2009). Crude oil and stock markets: Stability, instability, and bubbles. Energy Economics, 31(4), 559-568.

Mohanty, S. K., \& Nandha, M. (2011). Oil risk exposure: the case of the US oil and gas sector. Financial review, 46(1), 165-191.

Office for Budget Responsibility. Oil prices and the economy, March 2015. http://obr.uk/box/oil-prices-and-the-economy/

Oxford Economics (2014). UK economy may be boosted by falling oil prices, by John Bulford, December $10^{\text {th }}$, https://www.vistapartners.co.uk/uk-economy-may-beboosted-by-falling-oil-prices/

Pagano, M., \& Von Thadden, E. L. (2004). The European bond markets under EMU. Oxford review of economic policy, 20(4), 531-554.

Pastor, L., \& Veronesi, P. (2012). Uncertainty about government policy and stock prices. The journal of Finance, 67(4), 1219-1264. 
Phillips, P.C., \& Perron, P. (1988). Testing for a unit root in time series regression. Biometrika, 75(2), 335-346.

Reuters (2019). Oil price rise pushes up euro zone debt yields. By Dhara Ranasinghe. April, $23^{\text {rd }}$. https://uk.reuters.com/article/eurozone-bonds/oil-price-rise-pushesup-euro-zone-debt-yields-idUKL5N22515B.

Sadorsky, P. (2014). Modeling volatility and correlations between emerging market stock prices and the prices of copper, oil and wheat. Energy Economics, 43, 7281

Segal, P. (2011). Oil price shocks and the macroeconomy. Oxford Review of Economic Policy, 27(1), 169-185.

Shahzad, S. J. H., Naifar, N., Hammoudeh, S., \& Roubaud, D. (2017). Directional predictability from oil market uncertainty to sovereign credit spreads of oilexporting countries: Evidence from rolling windows and cross-quantilogram analysis. Energy Economics, 68, 327-339.

Tang, W., Wu, L., \& Zhang, Z. (2010). Oil price shocks and their short-and long-term effects on the Chinese economy. Energy Economics, 32, S3-S14.

Vrontisi, Z., Kitous, A., Saveyn, B., \& Vandyck, T. (2015). Impact of low oil prices on the EU economy (No. JRC98188). Joint Research Centre (Seville site).

Xekalaki, E., \& Degiannakis, S. (2010). ARCH models for financial applications. John Wiley \& Sons.

Wang, J., \& Ngene, G. (2017). Symmetric and asymmetric nonlinear causalities between oil prices and the US economic sectors. Review of Quantitative Finance and Accounting, 1-20.

Wang, Y., Wu, C., \& Yang, L. (2013). Oil price shocks and stock market activities: Evidence from oil-importing and oil-exporting countries. Journal of Comparative Economics, 41(4), 1220-1239.

Wegener, C., Basse, T., Kunze, F., \& von Mettenheim, H. J. (2016). Oil prices and sovereign credit risk of oil producing countries: an empirical investigation. Quantitative Finance, 16(12), 1961-1968. 


\section{TABLES}

\section{Table 1: Descriptive statistics}

\begin{tabular}{|c|c|c|c|c|c|c|c|c|c|}
\hline \multicolumn{10}{|c|}{ Panel A - Core countries } \\
\hline & Mean & Median & Max. & Min. & St.Dev. & Skewness & Kurtosis & $\mathrm{J}-\mathrm{B}$ & Prob. \\
\hline saus & 0.2666 & 0.2226 & 1.5390 & -0.0589 & 0.2675 & 1.7477 & 6.8298 & $229.6466 * * *$ & 0.0000 \\
\hline sbel & 0.4469 & 0.3065 & 2.6570 & -0.0156 & 0.4961 & 2.1033 & 7.9199 & $357.8997 * * *$ & 0.0000 \\
\hline sfin & 0.1639 & 0.1739 & 0.7845 & -0.1593 & 0.1612 & 0.4830 & 3.6371 & $11.4377 * * *$ & 0.0032 \\
\hline sfra & 0.2601 & 0.1462 & 1.5550 & -0.0132 & 0.2901 & 1.8523 & 7.0080 & $254.4446 * * *$ & 0.0000 \\
\hline snet & 0.1755 & 0.1483 & 0.6322 & -0.0512 & 0.1498 & 1.0489 & 3.8293 & $43.4613 * * *$ & 0.0000 \\
\hline \multicolumn{10}{|c|}{ Panel B - Periphery countries } \\
\hline & Mean & Median & Max. & Min. & St.Dev. & Skewness & Kurtosis & $\mathrm{J}-\mathrm{B}$ & Prob. \\
\hline sgre & 4.8634 & 0.6355 & 36.9890 & 0.0799 & 7.2359 & 2.1980 & 8.3443 & $361.1355^{* * *}$ & 0.0000 \\
\hline sire & 1.3456 & 0.3180 & 10.2210 & -0.2368 & 2.0364 & 1.8000 & 5.7016 & $152.7883 * * *$ & 0.0000 \\
\hline sita & 1.0925 & 0.4991 & 4.7950 & 0.0805 & 1.1815 & 1.4621 & 4.3509 & $78.2523 * * *$ & 0.0000 \\
\hline spor & 2.0178 & 0.4370 & 11.7670 & -0.0355 & 2.8724 & 1.7381 & 5.1430 & $125.7706^{* * *}$ & 0.0000 \\
\hline sspa & 1.0599 & 0.3406 & 5.5220 & -0.0518 & 1.3362 & 1.3832 & 4.0842 & $66.5812 * * *$ & 0.0000 \\
\hline \multicolumn{10}{|c|}{ Panel C - Oil-market specific variables and control variables } \\
\hline & Mean & Median & Max. & Min. & St.Dev. & Skewness & Kurtosis & $\mathrm{J}-\mathrm{B}$ & Prob. \\
\hline PRO & 72938.22 & 73448.49 & 81205.06 & 64798.05 & 3901.09 & -0.1050 & 2.4700 & 2.7762 & 0.2495 \\
\hline GEA & 0.0811 & 0.0600 & 0.6636 & -0.9557 & 0.3087 & -0.1050 & 2.5183 & 2.7993 & 0.2467 \\
\hline ROP & 29.6913 & 27.5764 & 65.4427 & 6.0534 & 14.0001 & 0.3122 & 1.8856 & $13.9384 * * *$ & 0.0009 \\
\hline EPU & 130.2943 & 119.9992 & 304.6002 & 47.6923 & 52.4946 & 0.6777 & 2.8061 & $16.0122 * * *$ & 0.0003 \\
\hline MPU & 100.1870 & 92.9904 & 370.4282 & 15.2935 & 52.4935 & 1.6620 & 7.8087 & $291.8889 * * *$ & 0.0000 \\
\hline VOL & 25.2468 & 23.1200 & 81.0300 & 11.9900 & 9.9416 & 1.8443 & 8.3227 & $358.2069 * * *$ & 0.0000 \\
\hline ROV & 33.3037 & 32.1759 & 102.6001 & 9.3144 & 14.2368 & 1.5768 & 7.4579 & $254.6974 * * *$ & 0.0000 \\
\hline
\end{tabular}

Note: This table summarises descriptive statistics (sample mean, median, maximum, minimum, standard deviation, skewness, kurtosis, the Jarque-Bera test statistic, and the p-value associated to the Jarque-Bera test statistic). Panel A shows 10-year sovereign yield spreads over Germany of core countries 
(Austria (saus), Belgium (sbel), Finland (sfin), France (sfra) and the Netherlands (snet)). Panel B displays 10-year sovereign yield spreads over Germany of periphery countries (Greece (sgre), Ireland (sire), Italy (sita), Portugal (spor) and Spain (sspa)). Panel C demonstrates the variables used for the estimation of the oil price shocks, world oil production (PRO), global economic activity index (GEA) and real oil price (ROP), as well as, the control variables European economic policy uncertainty index (EPU), the European monetary policy uncertainty index (MPU), the European stock market volatility index (VOL) and the realised oil price volatility (ROV). Asterisk * $(* *, * * *)$ denotes the $10 \%(5 \%, 1 \%)$ significance level. For the core countries, the time period spans from January 1999 to January 2016. For the periphery countries, the time period spans from January 2001 to January 2016. 
Table 2: Augmented Dickey-Fuller (1981) and Phillips-Perron (1988) unit root tests.

\begin{tabular}{|c|c|c|c|c|c|c|}
\hline \multicolumn{7}{|c|}{ Panel A - ADF test } \\
\hline & $\mathrm{C}$ & & $\mathrm{C} \& \mathrm{~T}$ & & $\mathrm{~N}$ & \\
\hline saus & -2.7088 & $*$ & -2.8710 & & -1.7652 & $*$ \\
\hline dsaus & -8.9493 & $* * *$ & -8.9279 & $* * *$ & -8.9704 & $* * *$ \\
\hline sbel & -2.1969 & & -2.3790 & & -1.2960 & \\
\hline dsbel & -8.7319 & $* * *$ & -8.7124 & $* * *$ & -8.7533 & $* * *$ \\
\hline sfin & -2.8028 & $*$ & -3.0270 & & -1.8239 & $*$ \\
\hline dsfin & -16.2675 & $* * *$ & -16.2329 & $* * *$ & -16.3079 & $* * *$ \\
\hline sfra & -1.6310 & & -2.2344 & & -0.8773 & \\
\hline dsfra & -10.6033 & $* * *$ & -10.5759 & $* * *$ & -10.6243 & $* * *$ \\
\hline snet & -2.9372 & $* *$ & -3.2860 & $*$ & -1.6924 & $*$ \\
\hline dsnet & -16.3071 & $* * *$ & -16.2648 & $* * *$ & -16.3470 & $* * *$ \\
\hline sgre & -1.7686 & & -2.0855 & & -1.2711 & \\
\hline dsgre & -9.1172 & $* * *$ & -9.0916 & $* * *$ & -9.1355 & $* * *$ \\
\hline sire & -1.7243 & & -1.6850 & & -1.3778 & \\
\hline dsire & -6.2504 & $* * *$ & -9.1809 & $* * *$ & -6.26856 & $* * *$ \\
\hline sita & -1.5794 & & -2.0051 & & -0.8458 & \\
\hline dsita & -6.0029 & $* * *$ & -6.0014 & $* * *$ & -6.0154 & $* * *$ \\
\hline spor & -2.0920 & & -2.6250 & & -1.4610 & \\
\hline dspor & -3.2814 & $* *$ & -3.2767 & $*$ & -3.2856 & $* * *$ \\
\hline sspa & -1.2199 & & -1.5896 & & -0.7525 & \\
\hline dsspa & -15.9153 & $* * *$ & -15.8773 & $* * *$ & -15.9523 & $* * *$ \\
\hline PRO & -0.5032 & & -2.6831 & & 1.8974 & \\
\hline DPRO & -14.9021 & $* * *$ & -14.8802 & $* * *$ & -14.6785 & $* * *$ \\
\hline GEA & -2.7226 & $*$ & -3.0175 & & -2.6725 & $* * *$ \\
\hline ROP & -1.8713 & & -1.5807 & & -0.5179 & \\
\hline DROP & -14.7486 & $* * *$ & -15.1536 & $* * *$ & -14.7706 & $* * *$ \\
\hline EPU & -4.2458 & $* * *$ & -5.4768 & $* * *$ & -0.9633 & \\
\hline MPU & -9.7248 & $* * *$ & -9.7814 & $* * *$ & -1.9544 & $* *$ \\
\hline VOL & -5.1159 & $* * *$ & -5.1084 & $* * *$ & -1.2408 & \\
\hline ROV & -4.1911 & $* * *$ & -4.3059 & $* * *$ & -1.0974 & \\
\hline \multicolumn{7}{|c|}{ Panel B - PP test } \\
\hline & $\mathrm{C}$ & & $\mathrm{C} \& \mathrm{~T}$ & & $\mathrm{~N}$ & \\
\hline saus & -2.9032 & $* *$ & -3.1092 & & -1.8194 & $*$ \\
\hline dsaus & -15.9998 & & -15.9623 & & -16.0356 & \\
\hline sbel & -2.0776 & & -2.2072 & & -1.4210 & \\
\hline dsbel & -13.1257 & $* * *$ & -13.0958 & $* * *$ & -13.1562 & $* * *$ \\
\hline sfin & -2.6528 & $*$ & -2.8500 & & -1.5929 & \\
\hline dsfin & -16.3711 & $* * *$ & -16.3363 & $* * *$ & -16.4130 & $* * *$ \\
\hline sfra & -2.0494 & & -2.9174 & & -1.1646 & \\
\hline dsfra & -15.8530 & $* * *$ & -15.8108 & $* * *$ & -15.8879 & $* * *$ \\
\hline snet & -2.8441 & $*$ & -3.2584 & $*$ & -1.4514 & \\
\hline dsnet & -16.4247 & $* * *$ & -16.3806 & $* * *$ & -16.4662 & $* * *$ \\
\hline
\end{tabular}




\begin{tabular}{ccccccc} 
sgre & -2.0743 & & -2.5055 & & -1.5425 & \\
dsgre & -12.6532 & $* * *$ & -12.6151 & $* * *$ & -12.6850 & $* * *$ \\
sire & -1.4466 & & -1.3400 & & -1.1536 & \\
dsire & -14.0574 & $* * *$ & -14.0594 & $* * *$ & -14.0968 & $* * *$ \\
sita & -1.5039 & & -1.9350 & & -0.7856 & \\
dsita & -14.3449 & $* * *$ & -14.3188 & $* * *$ & -14.3801 & $* * *$ \\
spor & -1.5697 & & -1.8957 & & -1.0399 & \\
dspor & -14.5391 & $* * *$ & -14.5143 & $* * *$ & -14.5668 & $* * *$ \\
sspa & -1.3098 & & -1.4360 & & -0.8224 & \\
dsspa & -15.8201 & $* * *$ & -15.7841 & $* * *$ & -15.9001 & $* * *$ \\
PRO & -0.4121 & & -2.6459 & & 2.0521 & \\
DPRO & -14.9939 & $* * *$ & -14.9702 & $* * *$ & -14.7027 & $* * *$ \\
GEA & -2.6226 & $*$ & -2.8973 & & -2.5606 & $* *$ \\
ROP & -2.0333 & & -1.9215 & & -0.6215 & \\
DROP & -14.7709 & $* * *$ & -15.1262 & $* * *$ & -14.7922 & $* * *$ \\
EPU & -4.0246 & $* * *$ & -5.3311 & $* * *$ & -0.5459 & \\
MPU & -9.9827 & $* * *$ & -10.0272 & $* * *$ & -3.2933 & $* * *$ \\
VOL & -4.9211 & $* * *$ & -4.9160 & $* * *$ & -1.3640 & \\
ROV & -7.0334 & $* * *$ & -7.4156 & $* * *$ & -1.6434 & $*$ \\
\hline
\end{tabular}

Note: The table reports the unit root tests of 10-year sovereign yield spreads over Germany of core and periphery countries (Austria (saus), Belgium (sbel), Finland (sfin), France (sfra), Netherlands (snet), Greece (sgre), Ireland (sire), Italy (sita), Portugal (spor) and Spain (sspa)). In addition, it reports the unit root tests of 10-year sovereign yield spreads over Germany of core and periphery countries in first differences (Austria (dsaus), Belgium (dsbel), Finland (dsfin), France (dsfra), Netherlands (dsnet), Greece (dsgre), Ireland (dsire), Italy (dsita), Portugal (dspor) and Spain (dsspa)). Furthermore, it shows the unit root tests of oil-market related variables of world oil production in levels (PRO) and first difference (DPRO), global economic activity index (GEA) and real oil price in level (ROP) and first difference (DROP), as well as, of the control variables European economic policy uncertainty index (EPU), the European monetary policy uncertainty index (MPU), the European stock market volatility index (VOL) and the realised oil price volatility (ROV) in levels. For the $\mathrm{ADF}$ and $\mathrm{PP}$ unit root tests the null hypothesis is that the series features a unit root. In both tests, $\mathrm{C}$ denotes constant term, $\mathrm{C} \& \mathrm{~T}$ denotes constant and time trend, $\mathrm{N}$ indicates no deterministic component in the test equation. Asterisk $*(* * * * *)$ denotes the $10 \%(5 \%, 1 \%)$ significance level. For the core countries, the time period spans from January 1999 to January 2016. For the periphery countries, the time period spans from January 2001 to January 2016. 
Table 3: Unconditional correlations between sovereign yield spreads and oil price shocks - whole sample

\begin{tabular}{cccc}
\hline & $\begin{array}{c}\text { Supply-side } \\
\text { shock }\end{array}$ & $\begin{array}{c}\text { Aggregate } \\
\text { demand shock }\end{array}$ & $\begin{array}{c}\text { Precautionary } \\
\text { demand shock }\end{array}$ \\
\hline saus & -0.0676 & 0.0982 & -0.1294 \\
sbel & -0.0721 & 0.1678 & -0.1417 \\
sfin & -0.0922 & 0.0454 & -0.1135 \\
sfra & -0.0596 & 0.1084 & -0.1229 \\
snet & -0.0243 & -0.0162 & -0.1475 \\
sgre & 0.0110 & 0.0002 & -0.1066 \\
sire & -0.1486 & 0.0459 & 0.0803 \\
sita & -0.0770 & 0.0684 & -0.1189 \\
spor & -0.0994 & 0.1071 & -0.0002 \\
sspa & -0.0105 & 0.0275 & -0.0681 \\
\hline Note: Unconditional correlations between 10-year sovereign yield spreads \\
over Germany of core and periphery countries in first differences and \\
different oil price shocks. Core countries: Austria (saus), Belgium (sbel), \\
Finland (sfin), France (sfra) and the Netherlands (snet). Periphery countries: \\
Greece (sgre), Ireland (sire), Italy (sita), Portugal (spor) and Spain (sspa). \\
For the core countries, the time period spans from January 1999 to January \\
2016. For the periphery countries, the time period spans from January 2001 \\
to January 2016.
\end{tabular}


Table 4: Unconditional correlations among sovereign yield spreads and oil price shocks - divided sample

\begin{tabular}{|c|c|c|c|}
\hline & $\begin{array}{c}\text { Supply-side } \\
\text { shock }\end{array}$ & $\begin{array}{c}\text { Aggregate } \\
\text { demand shock }\end{array}$ & $\begin{array}{l}\text { Precautionary } \\
\text { demand shock }\end{array}$ \\
\hline \multicolumn{4}{|c|}{ Panel A - Pre-Great Recession } \\
\hline saus & -0.1971 & -0.0886 & 0.1777 \\
\hline sbel & -0.0549 & -0.0703 & 0.1240 \\
\hline sfin & -0.1921 & -0.0387 & 0.1701 \\
\hline sfra & -0.0708 & -0.0742 & -0.0162 \\
\hline snet & 0.0296 & -0.1111 & 0.0597 \\
\hline sgre & 0.1030 & 0.0374 & 0.1347 \\
\hline sire & 0.0857 & -0.0700 & 0.0119 \\
\hline sita & 0.0771 & -0.0630 & 0.0444 \\
\hline spor & 0.1414 & 0.0416 & 0.1389 \\
\hline sspa & 0.0823 & 0.0919 & 0.0441 \\
\hline \multicolumn{4}{|c|}{ Panel B - Post-Great Recession } \\
\hline saus & -0.0689 & 0.1220 & -0.2616 \\
\hline sbel & -0.1289 & 0.2018 & -0.2778 \\
\hline sfin & -0.0284 & 0.0698 & -0.3257 \\
\hline sfra & 0.0853 & 0.1428 & -0.2032 \\
\hline snet & -0.0826 & 0.0059 & -0.3069 \\
\hline sgre & 0.0130 & 0.0046 & -0.1617 \\
\hline sire & -0.2318 & 0.0538 & -0.1234 \\
\hline sita & 0.1289 & 0.0829 & -0.1872 \\
\hline spor & -0.1616 & 0.1240 & -0.0069 \\
\hline sspa & -0.0250 & 0.0324 & -0.1049 \\
\hline \multicolumn{4}{|c|}{$\begin{array}{l}\text { Note: Unconditional correlations between 10-year sovereign yield spreads } \\
\text { over Germany of core and periphery countries in first differences and } \\
\text { different oil price shocks. Core countries: Austria (saus), Belgium (sbel), } \\
\text { Finland (sfin), France (sfra) and the Netherlands (snet). Periphery countries: } \\
\text { Greece (sgre), Ireland (sire), Italy (sita), Portugal (spor) and Spain (sspa). } \\
\text { For the core countries, the time period spans from January } 1999 \text { to January } \\
\text { 2016. For the periphery countries, the time period spans from January } 2001 \\
\text { to January 2016. The pre-Great Recession extends until August 2008, } \\
\text { whereas the post-Great Recession begins in September 2008. }\end{array}$} \\
\hline
\end{tabular}


FIGURES

Figure 1: EU's oil import dependency

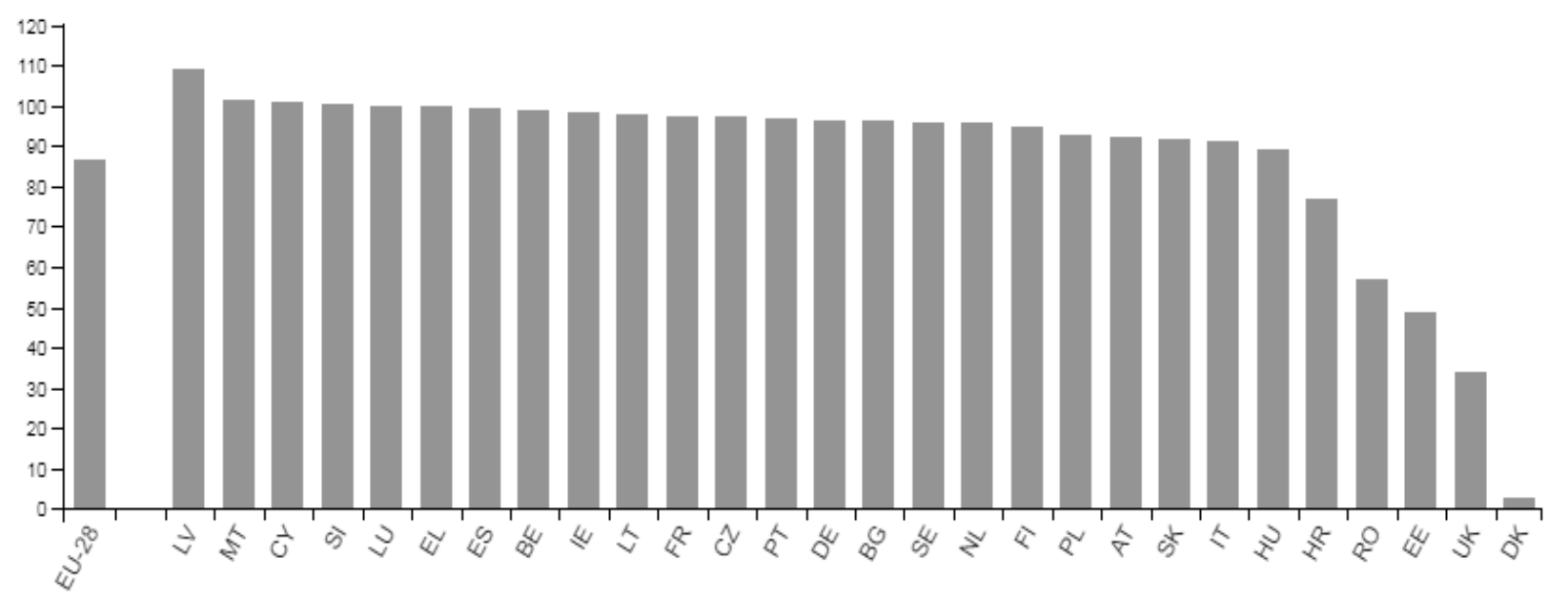

Note: The figure shows the import dependency of crude oil in EU-28 during 2016. Values over 100 percent denote a stock build. Source: Eurostat 


\section{Figure 2: Time series employed in the study}
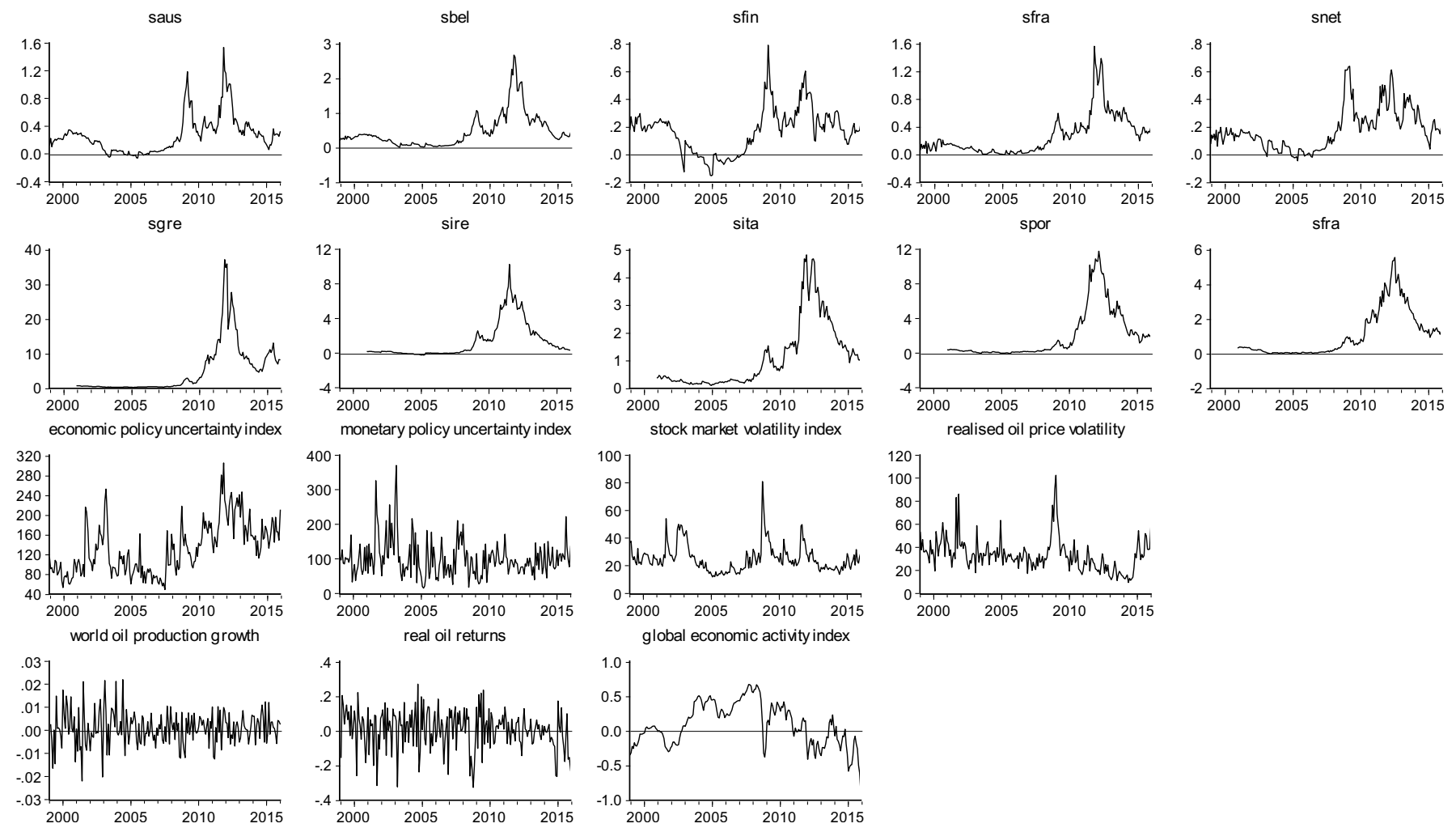

Note: This Figure exhibits the evolution of the series during the sample period. In the first row, 10-year sovereign yield spreads over Germany of the core countries (Austria (saus), Belgium (sbel), Finland (sfin), France (sfra) and the Netherlands (snet)) are represented. In the second row, 10-year sovereign yield spreads over Germany of the periphery countries (Greece (sgre), Ireland (sire), Italy (sita), Portugal (spor) and Spain (sspa)) are depicted. In the third row, the European economic policy uncertainty index, the European monetary policy uncertainty index, the European stock market volatility index and the realised oil price 
volatility are shown. In the fourth row, world oil production growth, real oil returns and global economic activity index are depicted. For the core countries, the time period spans from January 1999 to January 2016. For the periphery countries, the time period spans from January 2001 to January 2016 

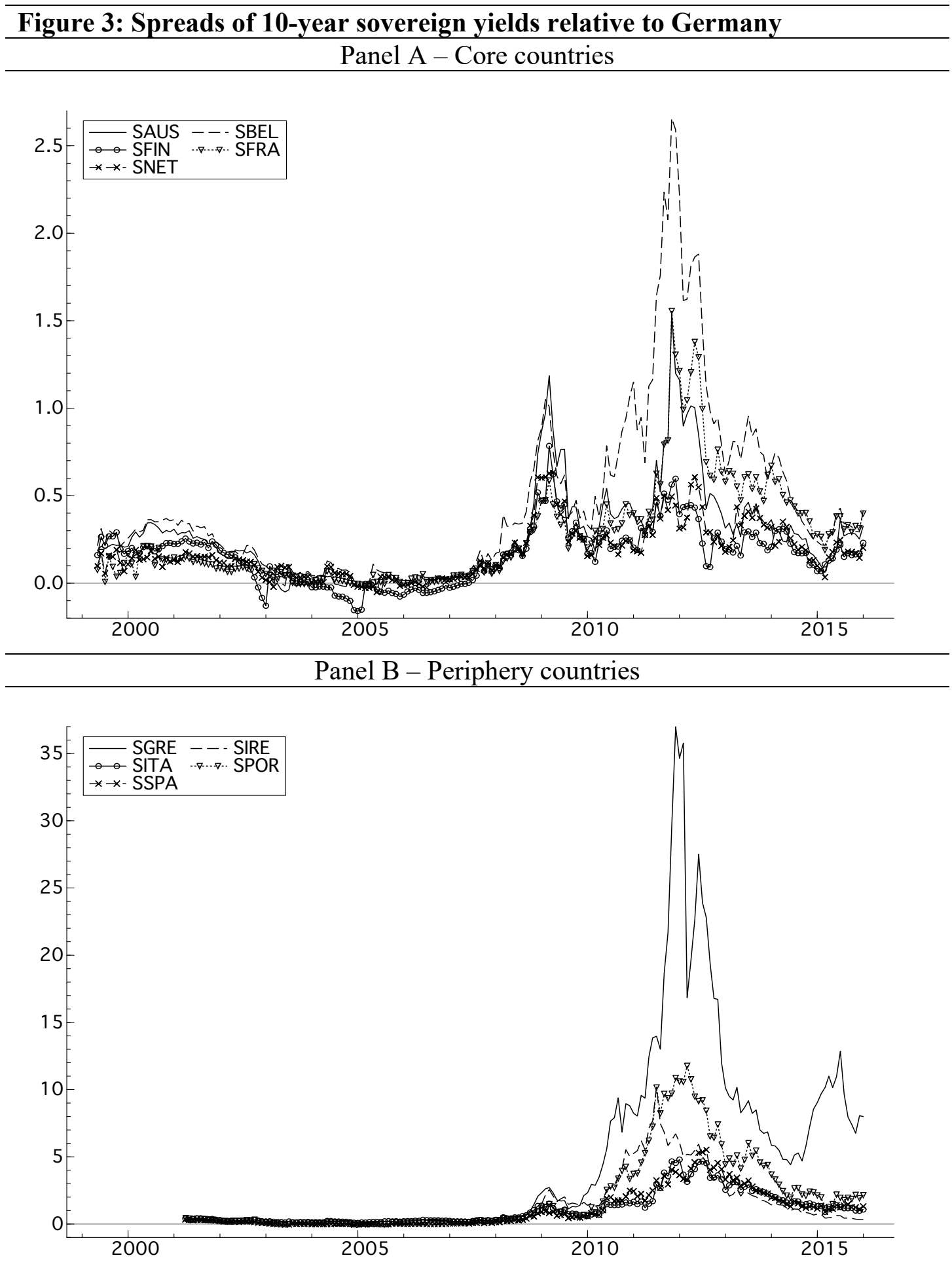

Note: This Figure depicts variation over time of 10-year sovereign yield spreads over Germany. For the core countries (Austria (saus), Belgium (sbel), Finland (sfin), France (sfra) and the Netherlands (snet)), the time period spans from January 1999 to January 2016. For the periphery countries (Greece (sgre), Ireland (sire), Italy (sita), Portugal (spor) and Spain (sspa)), the time period runs from January 2001 to January 2016. 

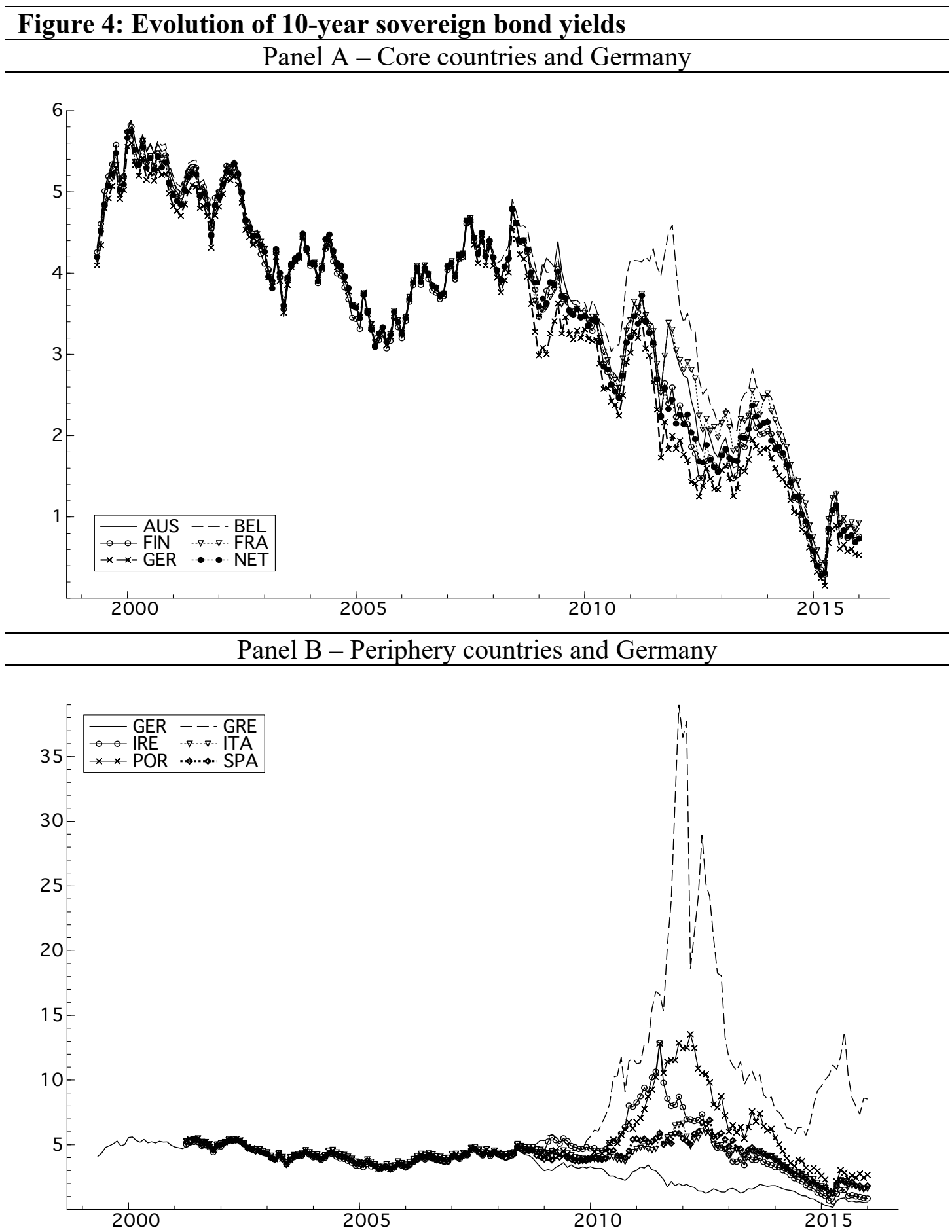

Note: This Figure depicts variation over time of 10 -year sovereign bond yields. For the core countries (Austria (aus), Belgium (bel), Finland (fin), France (fra) and the Netherlands (net)), the time period spans from January 1999 to January 2016. For the periphery countries (Greece (gre), Ireland (ire), Italy (ita), Portugal (por) and Spain (spa)), the time period runs from January 2001 to January 2016. Germany (ger) represents the anchor country. 


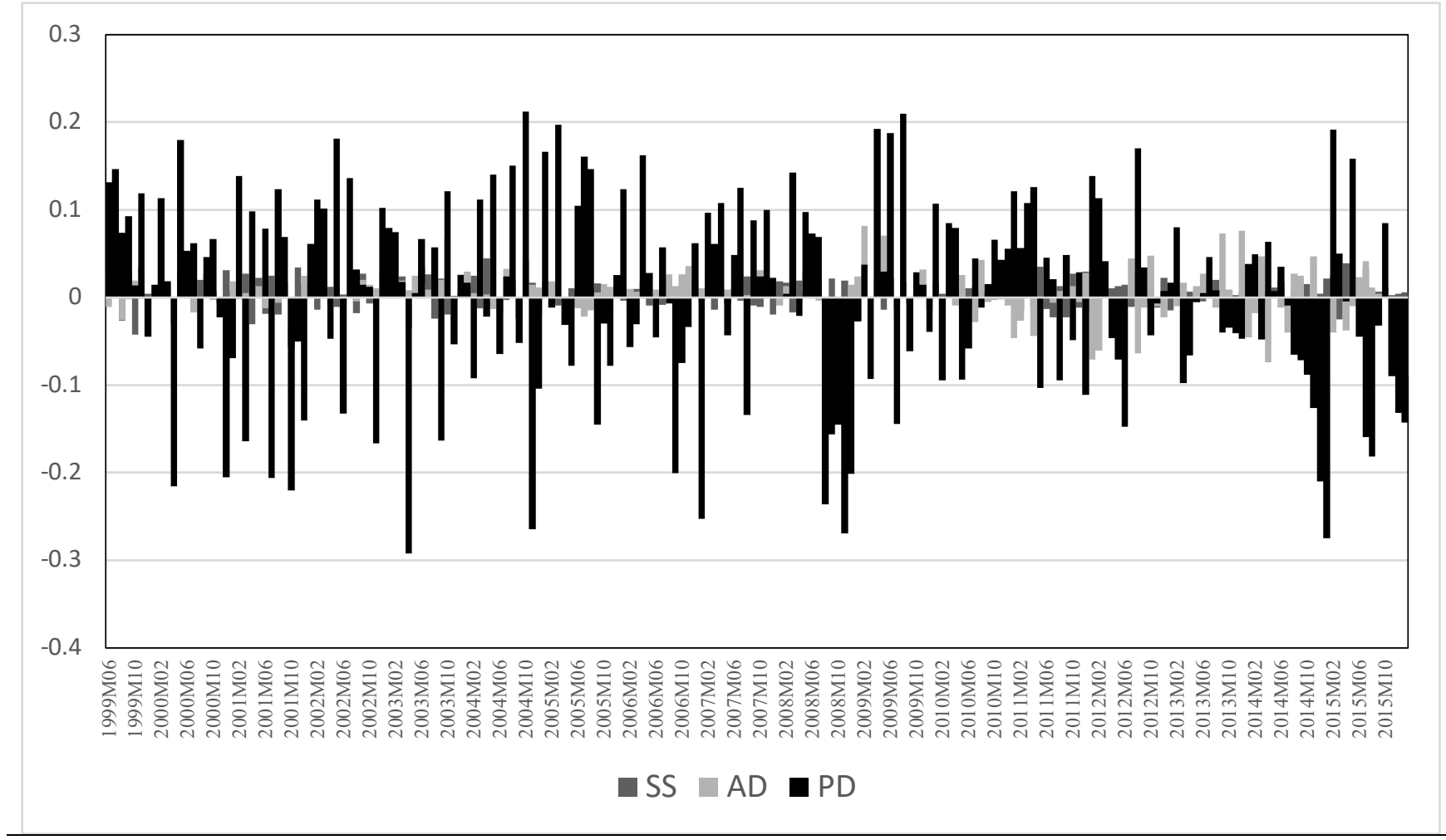

Note: This Figure exhibits the historical decomposition of the real oil price returns at each point in time based on the origin of the oil price shock. SS denotes the supply-side shock, AD represents the aggregate demand shock and PD reflects the precautionary demand shock. The sample period runs from January 1999 to January 2016. 


\section{Figure 6: Time-varying correlations between oil price shocks and the 10-year sovereign yield spread}

\section{of Austria}
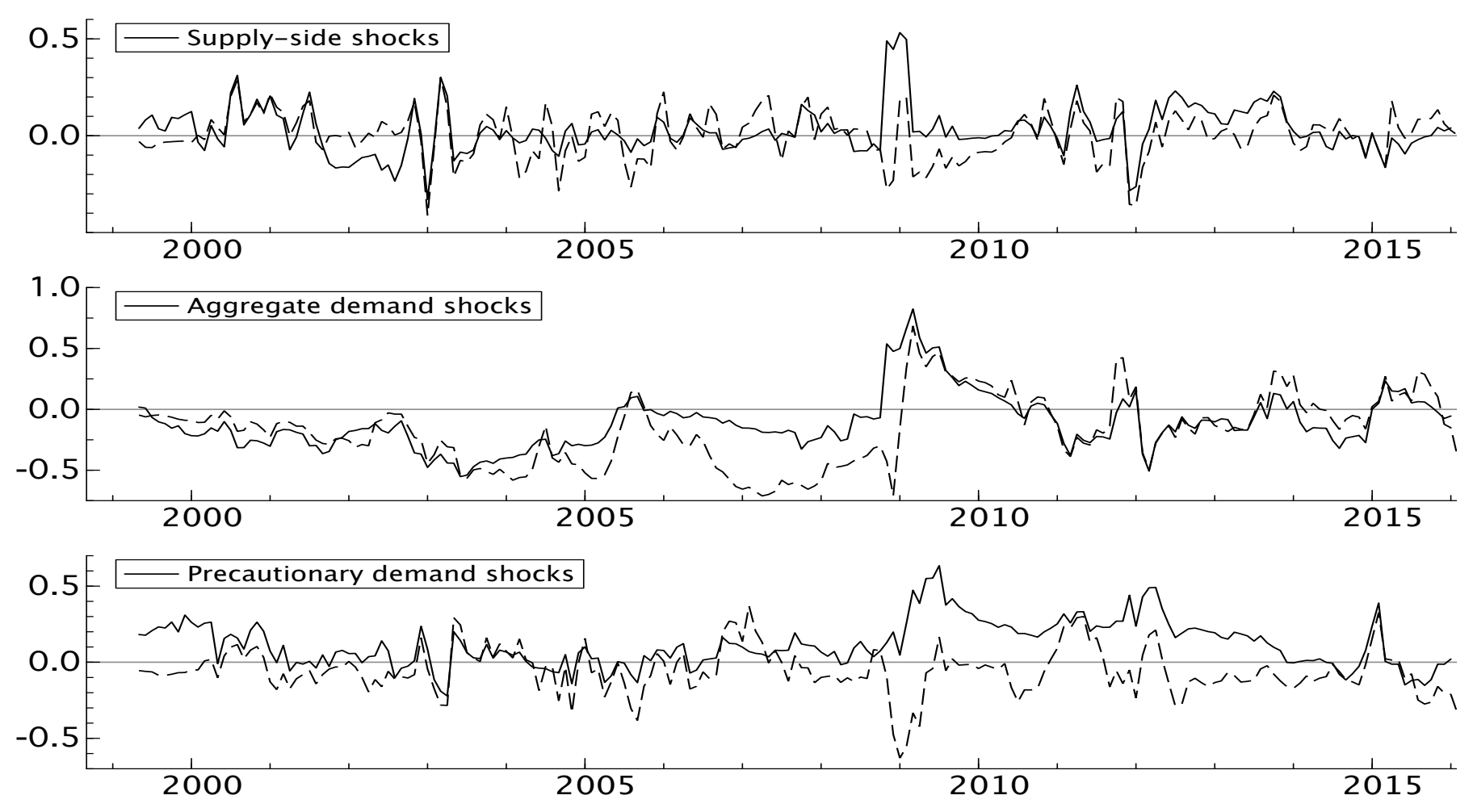

Note: This Figure depicts the time-varying correlation between supply-side shocks, aggregate demand shocks, precautionary demand shocks and the 10-year Austrian sovereign yield spread (the difference between the Austrian sovereign bond yield and the yield on the German Bund). The solid line (dashed line) shows the correlation that includes (excludes) the control variables related to the omitted variable bias issue. The time period spans from January 1999 to January 2016. 
Figure 7: Time-varying correlations between oil price shocks and the 10-year sovereign yield spread of Belgium
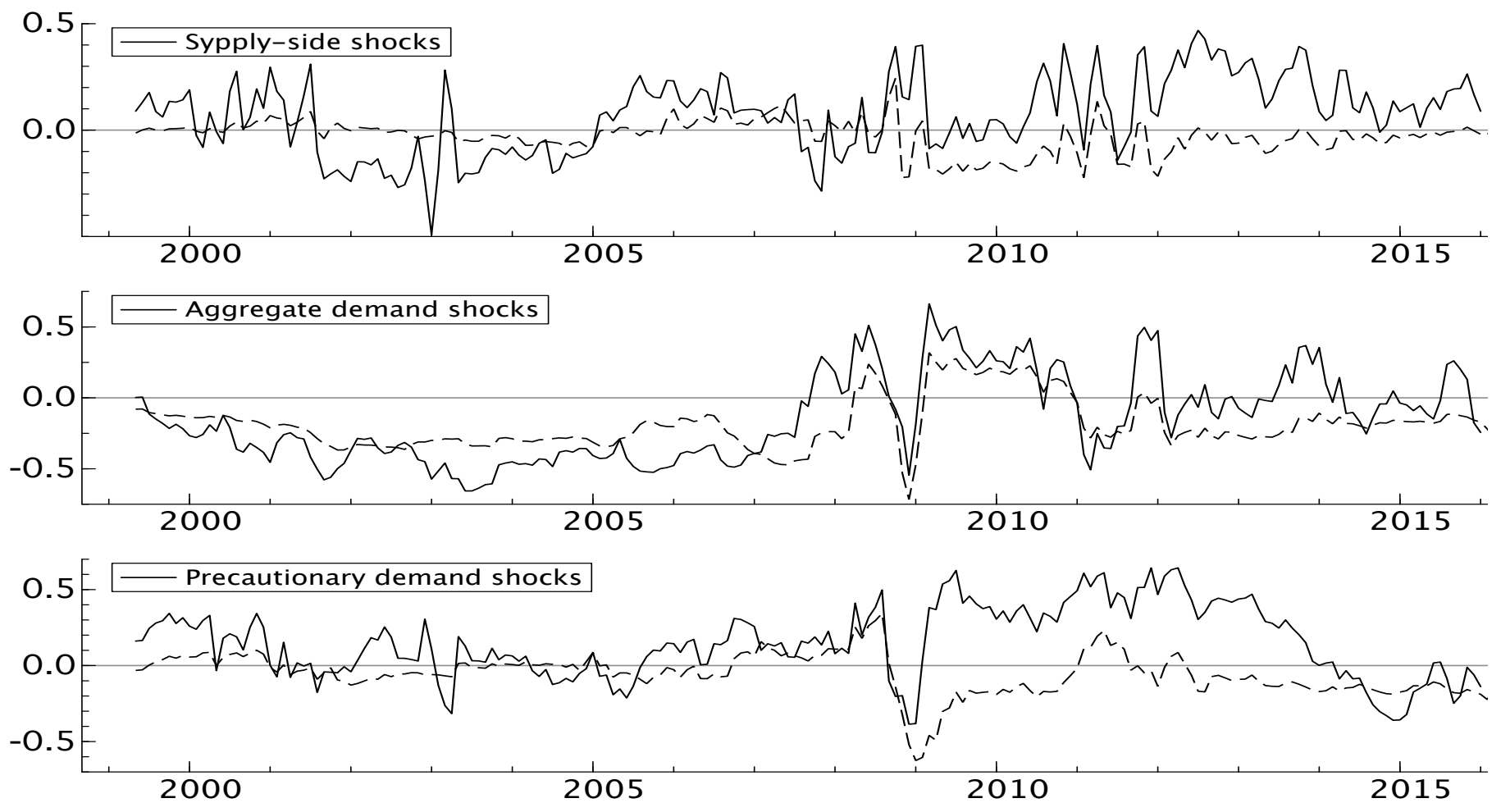

Note: This Figure depicts the time-varying correlation between supply-side shocks, aggregate demand shocks, precautionary demand shocks and the 10-year Belgian sovereign yield spread (the difference between the Belgian sovereign bond yield and the yield on the German Bund). The solid line (dashed line) shows the correlation that includes (excludes) the control variables related to the omitted variable bias issue. The time period spans from January 1999 to January 2016 
Figure 8: Time-varying correlations between oil price shocks and the 10-year sovereign yield spread of Finland
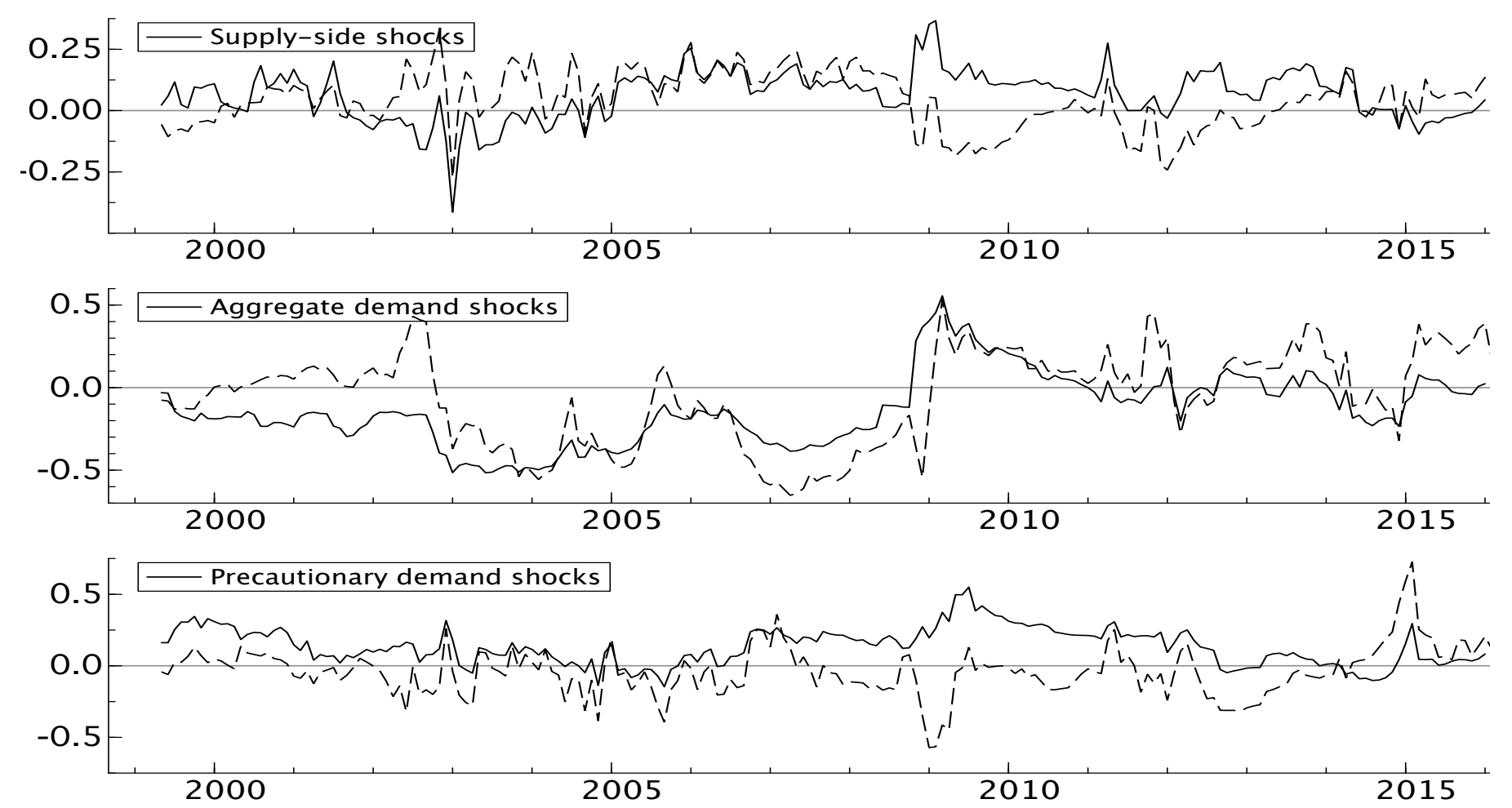

Note: This Figure depicts the time-varying correlation between supply-side shocks, aggregate demand shocks, precautionary demand shocks and the 10-year Finnish sovereign yield spread (the difference between the Finnish sovereign bond yield and the yield on the German Bund). The solid line (dashed line) shows the correlation that includes (excludes) the control variables related to the omitted variable bias issue. The time period spans from January 1999 to January 2016. 


\section{Figure 9: Time-varying correlations between oil price shocks and the 10-year sovereign yield spread}

\section{of France}
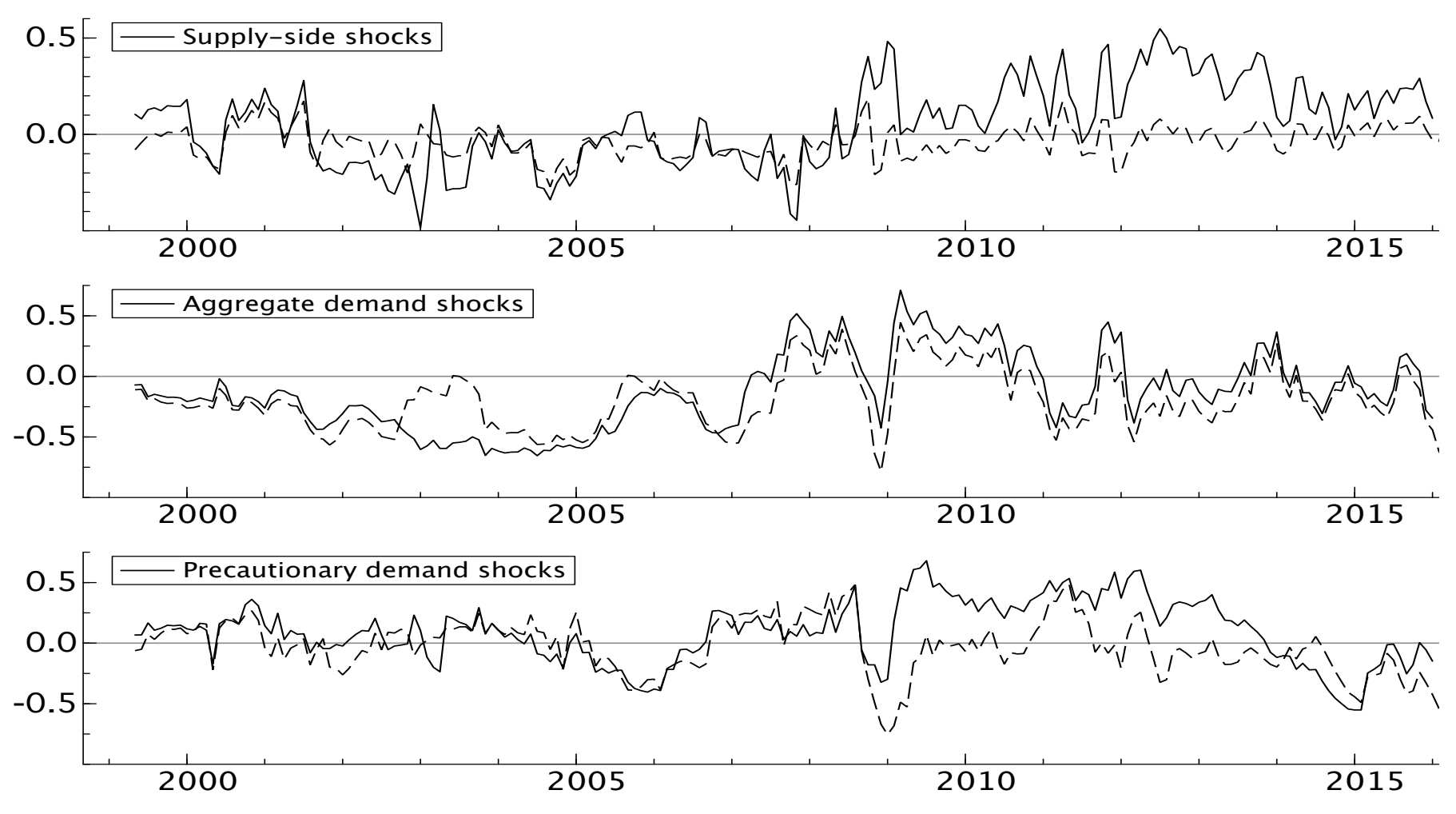

Note: This Figure depicts the time-varying correlation between supply-side shocks, aggregate demand shocks, precautionary demand shocks and the 10-year French sovereign yield spread (the difference between the French sovereign bond yield and the yield on the German Bund). The solid line (dashed line) shows the correlation that includes (excludes) the control variables related to the omitted variable bias issue. The time period spans from January 1999 to January 2016. 
Figure 10: Time-varying correlations between oil price shocks and the 10-year sovereign yield spread of the Netherlands
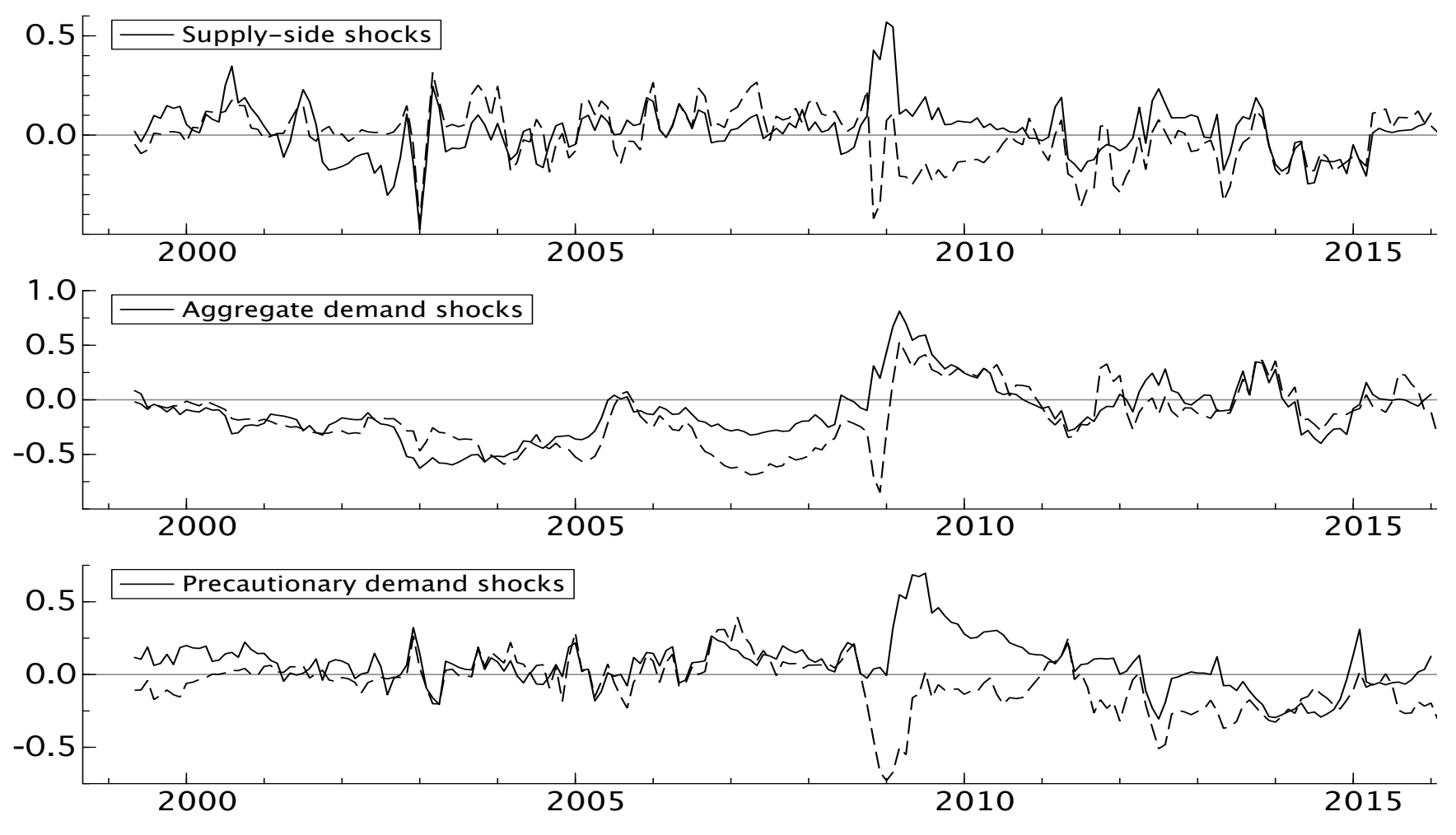

Note: This Figure depicts the time-varying correlation between supply-side shocks, aggregate demand shocks, precautionary demand shocks and the 10-year Dutch sovereign yield spread (the difference between the Dutch sovereign bond yield and the yield on the German Bund). The solid line (dashed line) shows the correlation that includes (excludes) the control variables related to the omitted variable bias issue. The time period spans from January 1999 to January 2016. 
Figure 11: Time-varying correlations between oil price shocks and the 10-year sovereign yield spread of Greece
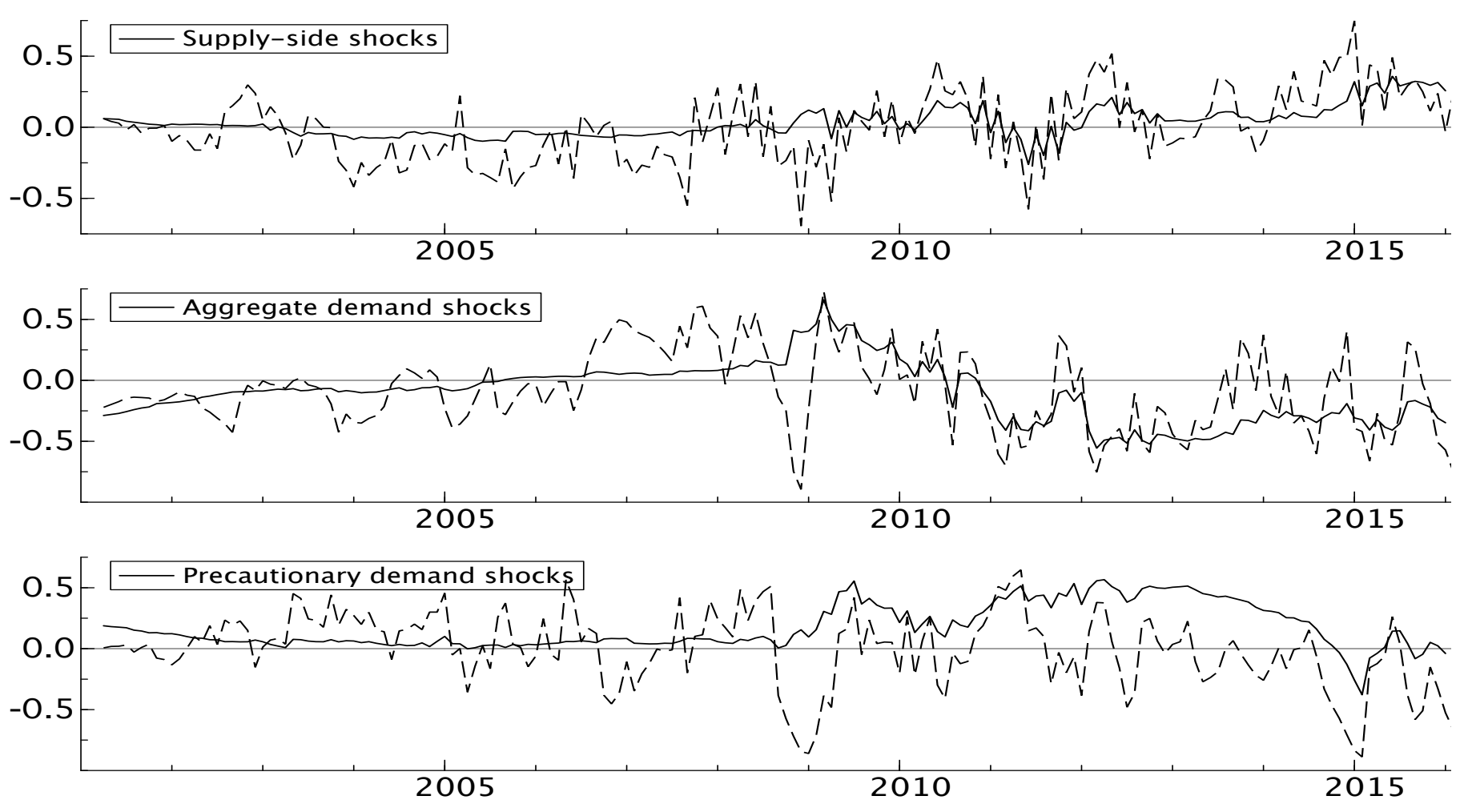

Note: This Figure depicts the time-varying correlation between supply-side shocks, aggregate demand shocks, precautionary demand shocks and the 10-year Greek sovereign yield spread (the difference between the Greek sovereign bond yield and the yield on the German Bund). The solid line (dashed line) shows the correlation that includes (excludes) the control variables related to the omitted variable bias issue. The time period spans from January 2001 to January 2016. 


\section{Figure 12: Time-varying correlations between oil price shocks and the 10-year sovereign yield spread}

\section{of Ireland}
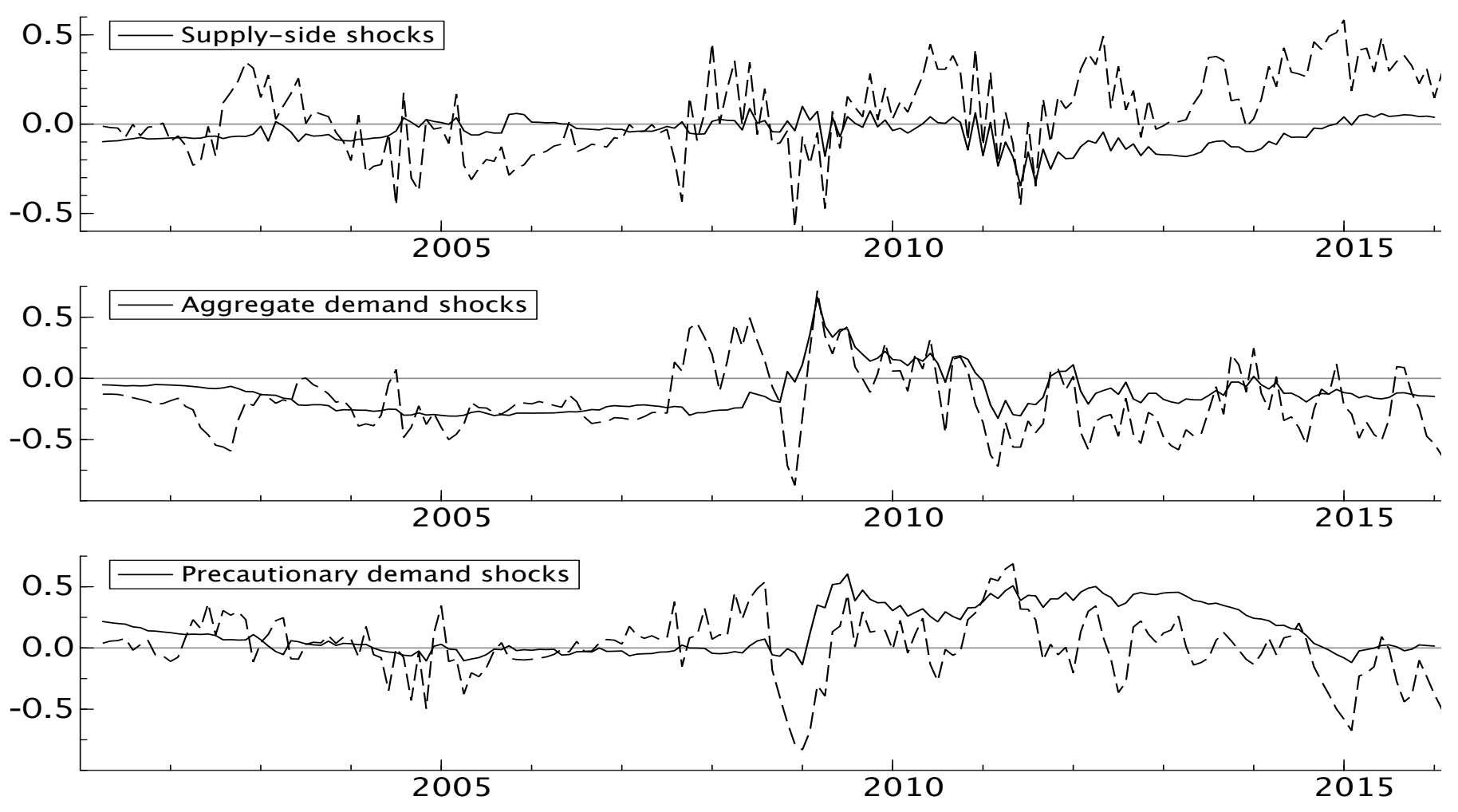

Note: This Figure depicts the time-varying correlation between supply-side shocks, aggregate demand shocks, precautionary demand shocks and the 10-year Irish sovereign yield spread (the difference between the Irish sovereign bond yield and the yield on the German Bund). The solid line (dashed line) shows the correlation that includes (excludes) the control variables related to the omitted variable bias issue. The time period spans from January 2001 to January 2016 


\section{Figure 13: Time-varying correlations between oil price shocks and the 10-year sovereign yield}

\section{spread of Italy}
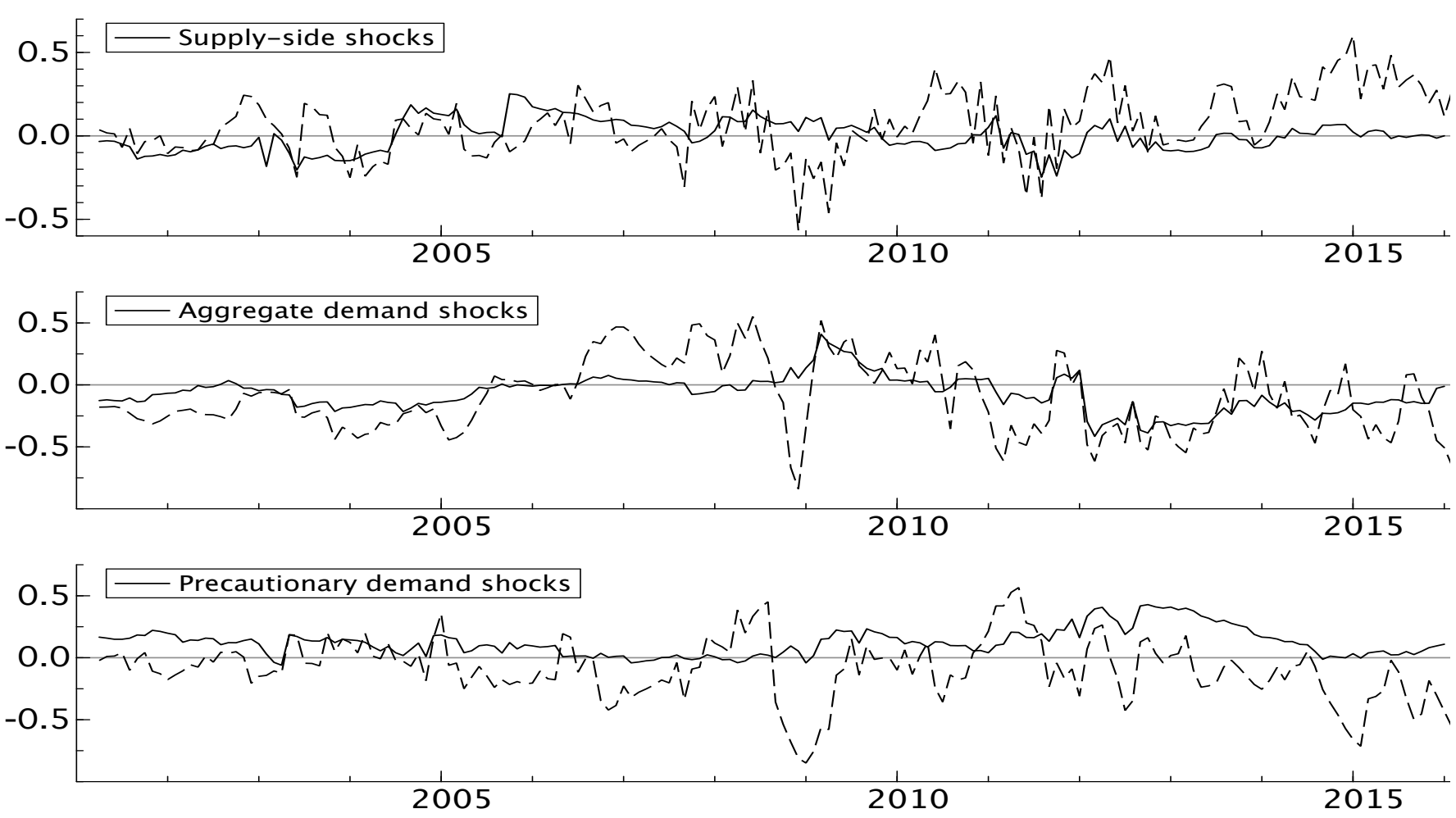

Note: This Figure depicts the time-varying correlation between supply-side shocks, aggregate demand shocks, precautionary demand shocks and the 10-year Italian sovereign yield spread (the difference between the Italian sovereign bond yield and the yield on the German Bund). The solid line (dashed line) shows the correlation that includes (excludes) the control variables related to the omitted variable bias issue. The time period spans from January 2001 to January 2016. 
Figure 14: Time-varying correlations between oil price shocks and the 10-year sovereign yield spread of Portugal
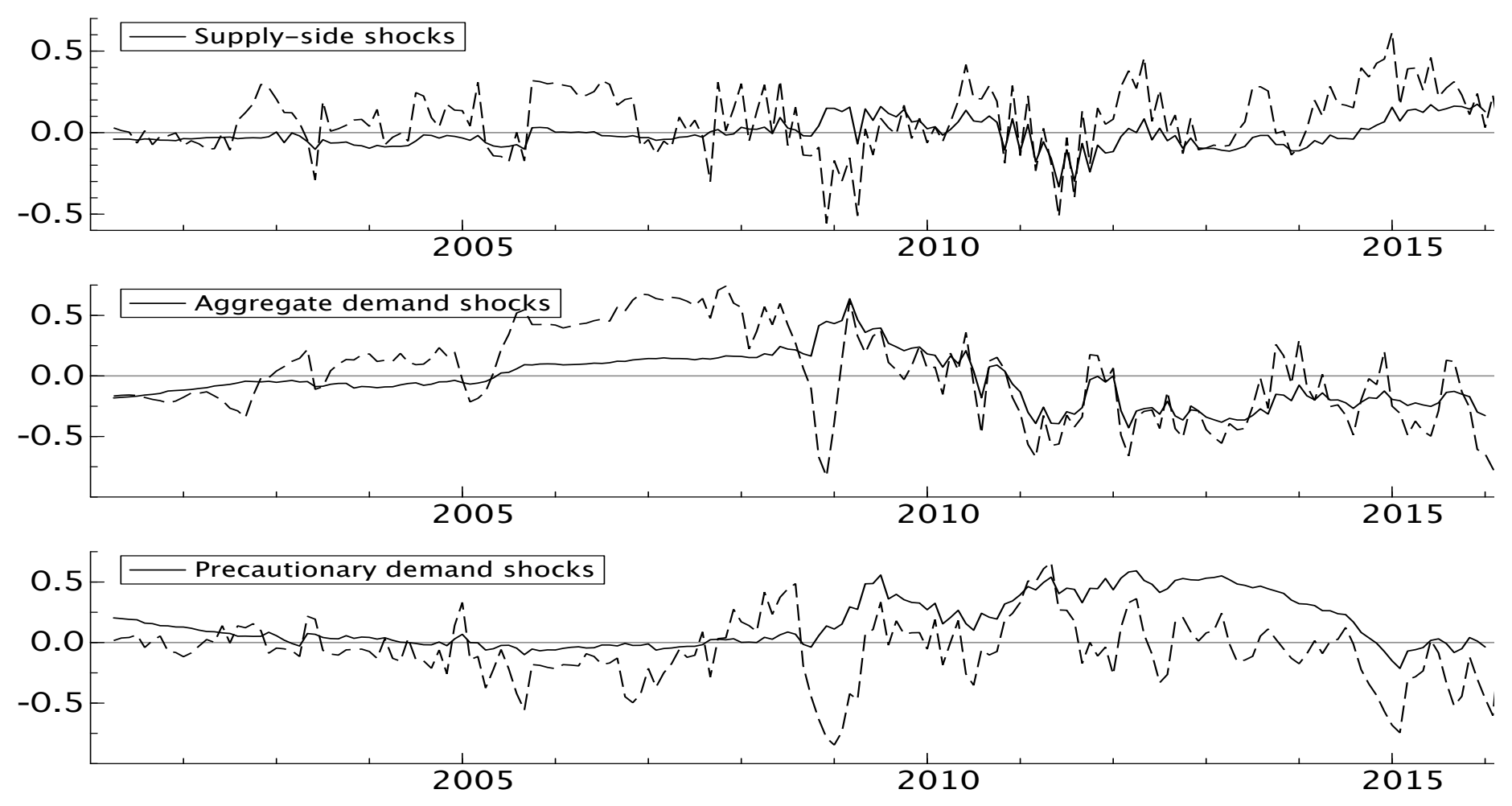

Note: This Figure depicts the time-varying correlation between supply-side shocks, aggregate demand shocks, precautionary demand shocks and the 10-year Portuguese sovereign yield spread (the difference between the Portuguese sovereign bond yield and the yield on the German Bund). The solid line (dashed line) shows the correlation that includes (excludes) the control variables related to the omitted variable bias issue. The time period spans from January 2001 to January 2016. 
Figure 15: Time-varying correlations between oil price shocks and the 10-year sovereign yield spread of Spain
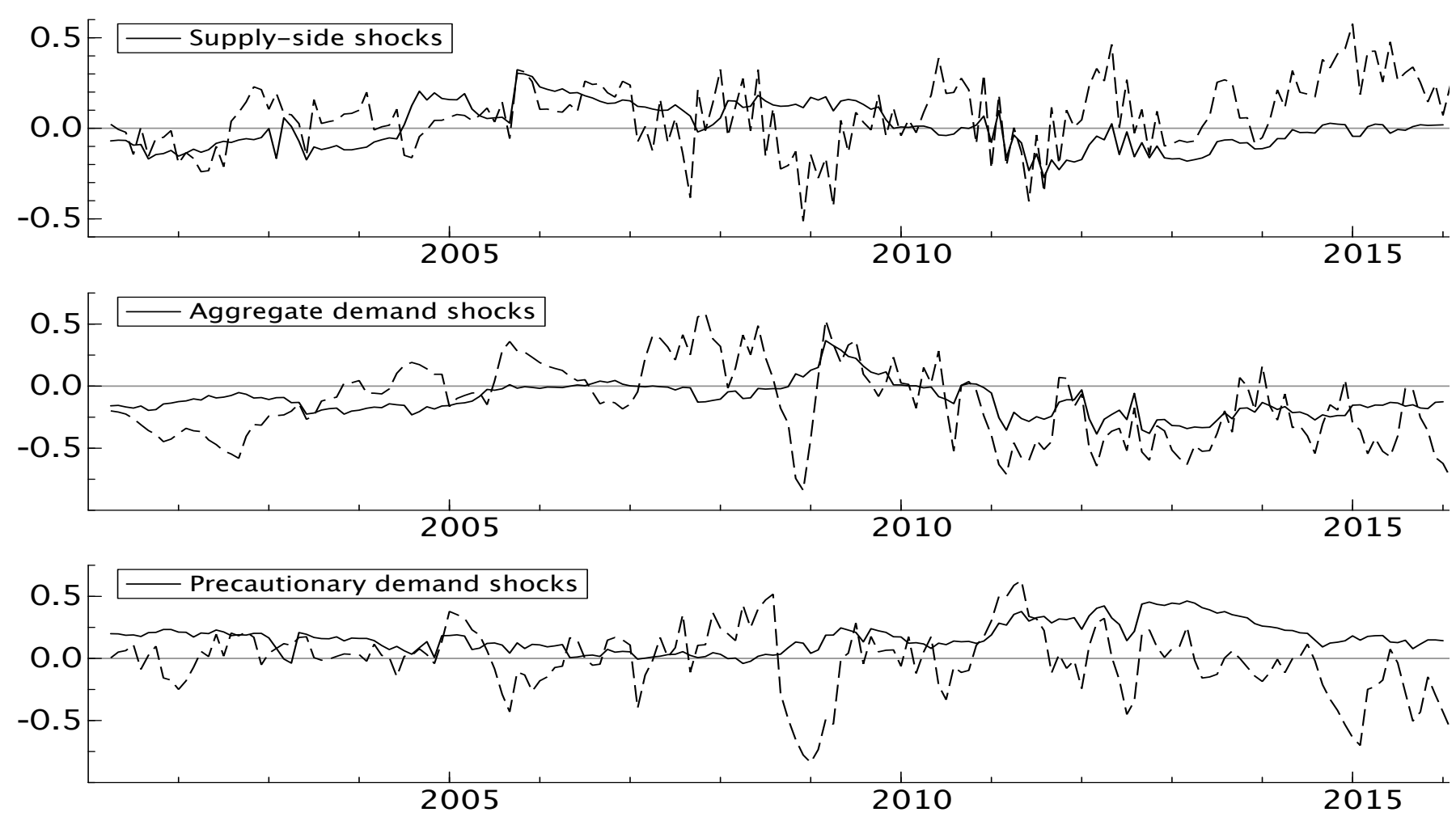

Note: This Figure depicts the time-varying correlation between supply-side shocks, aggregate demand shocks, precautionary demand shocks and the 10-year Spanish sovereign yield spread (the difference between the Spanish sovereign bond yield and the yield on the German Bund). The solid line (dashed line) shows the correlation that includes (excludes) the control variables related to the omitted variable bias issue. The time period spans from January 2001 to January 2016. 